University of Louisville

ThinkIR: The University of Louisville's Institutional Repository

\title{
The effects of moderate alcohol consumption and inflammation on the hepatic matrisome and the renal cortex proteome.
}

Christine E. Dolin

University of Louisville

Follow this and additional works at: https://ir.library.louisville.edu/etd

Part of the Medical Toxicology Commons

\section{Recommended Citation}

Dolin, Christine E., "The effects of moderate alcohol consumption and inflammation on the hepatic matrisome and the renal cortex proteome." (2017). Electronic Theses and Dissertations. Paper 2649. https://doi.org/10.18297/etd/2649

This Master's Thesis is brought to you for free and open access by ThinkIR: The University of Louisville's Institutional Repository. It has been accepted for inclusion in Electronic Theses and Dissertations by an authorized administrator of ThinkIR: The University of Louisville's Institutional Repository. This title appears here courtesy of the author, who has retained all other copyrights. For more information, please contact thinkir@louisville.edu. 
THE EFFECTS OF MODERATE ALCOHOL CONSUMPTION AND INFLAMMATION ON THE HEPATIC MATRISOME AND THE RENAL CORTEX PROTEOME

By

Christine E. Dolin

B.S., University of Louisville, 2015

\begin{abstract}
A Thesis
Submitted to the Faculty of the

School of Medicine of the University of Louisville

In Partial Fulfillment of the Requirements

for the Degree of
\end{abstract}

Master of Science in Pharmacology and Toxicology

Department of Pharmacology and Toxicology

University of Louisville

Louisville, KY

May 2017 

THE EFFECTS OF MODERATE ALCOHOL CONSUMPTION AND INFLAMMATION ON THE HEPATIC MATRISOME AND THE RENAL CORTEX PROTEOME

By

Christine E. Dolin

B.S., University of Louisville, 2015

Thesis Approved on

$04 / 12 / 2017$

by the following Thesis Committee:

Gavin E. Arteel, Ph.D.

Michael L. Merchant, Ph.D.

Michelle T. Barati, Ph.D.

Juliane I. Beier, Ph.D.

Jonathan H. Freedman, Ph.D.

Gary W. Hoyle, Ph.D. 


\section{DEDICATION}

This thesis is dedicated to my parents

\section{Owen Dolin}

and

Ann Dolin

for their constant encouragement and support

in all my endeavors. 


\section{ACKNOWLEDGEMENTS}

I would like to thank my mentors, Dr. Gavin Arteel and Dr. Michael Merchant, first for their guidance and support in my thesis research and also for their confidence in my abilities as a scientific researcher. Their encouragement during my first scientific investigations as an undergraduate researcher and throughout my graduate career has been instrumental in the success of my research. Many thanks to my committee, Dr. Michelle Barati, Dr. Juliane Beier, Dr. Jonathan Freedman, and Dr. Gary Hoyle, for their comments and assistance. 


\title{
ABSTRACT \\ THE EFFECTS OF MODERATE ALCOHOL CONSUMPTION AND INFLAMMATION ON THE HEPATIC MATRISOME AND THE RENAL CORTEX PROTEOME
}

\author{
Christine E. Dolin
}

$04 / 12 / 2017$

Background. The association of chronic ethanol $(\mathrm{EtOH})$ consumption with extracellular matrix (ECM) changes in alcoholic liver disease (ALD) is well established in the context of hepatic fibrosis. However, it is becoming increasingly understood that the hepatic ECM responds dynamically to stress well before fibrosis. The term "transitional tissue remodeling" describes qualitative and quantitative ECM changes in response to injury that do not alter the overall architecture of the organ; these ECM changes may contribute to early disease initiation and/or progression. The nature and magnitude of these changes to the ECM are currently poorly understood. In contrast to the liver, EtOH consumption is not considered a risk factor for disease in the kidney. However, the effects of ethanol on the kidney at a molecular level are largely unknown. Methods. The goal of this work was to characterize the impact of 6 weeks EtOH diet and/or acute lipopolysaccharide (LPS) on the hepatic ECM proteome ('matrisome') and the renal cortex proteome. Liver sections were processed in a series of increasingly rigorous extraction buffers to separate proteins by 'age' and crosslinking. Kidney cortex proteins were extracted in lysis buffer. Extracted proteins were identified using liquid chromatography-tandem mass spectrometry (LC-MS/MS). Results. Both EtOH and LPS dramatically increased the number of hepatic matrisome proteins $\sim 25 \%$. The enhancement of LPS-induced liver damage by ethanol preexposure was associated with unique protein changes. In the renal cortex, 170 of 1863 proteins were significantly differentially abundant at $F C \geq 1.2$ across groups. Ingenuity Pathways Analysis results show EtOH dysregulated the Nrf2-mediated pathway. Western blot and 
immunohistochemistry of Nrf2 target proteins validate proteomic findings. Transcriptomic analysis of the renal cortex reinforce proteomic findings and provide additional insight into Nrf2 pathway regulation.

Conclusions. An extraction method to enrich the hepatic ECM was developed and characterized. The results demonstrate that the hepatic matrisome responds dynamically to both acute (LPS) and chronic (ethanol) stresses, long before more dramatic fibrotic changes to the liver. These changes may contribute, at least in part, to the pathologic responses to these stresses. It is also interesting that several ECM proteins responded similarly to both stresses, suggesting a common mechanism in both models. The study on the effects of EtOH and/or LPS on the renal transcriptome and proteome supported expected observations and revealed new changes in proteins, transcripts, and pathways. These changes provide insight into mechanisms by which EtOH affects the kidney and alters response to a second pathologic stimulus. 
TABLE OF CONTENTS

PAGE

DEDICATION

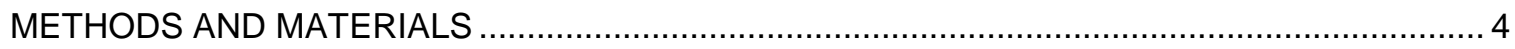

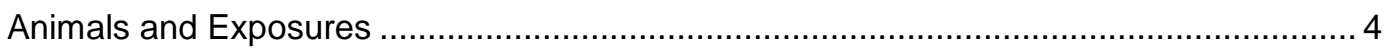

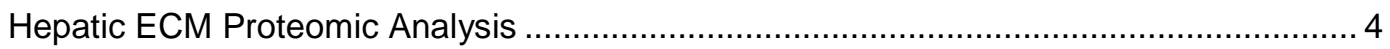

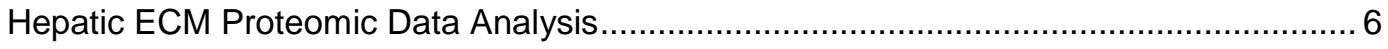

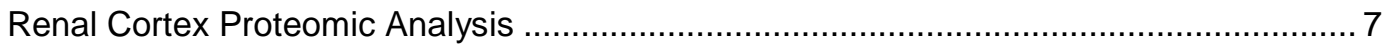

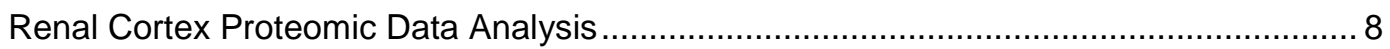

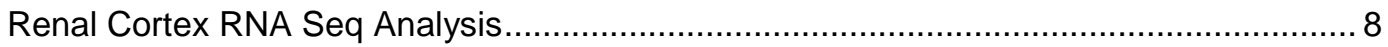

Renal Cortex Immunoblots, Immunohistochemistry, and Catalase Activity Assay ............ 9

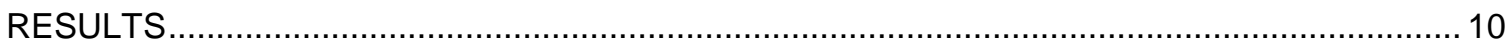

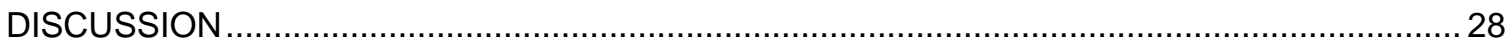

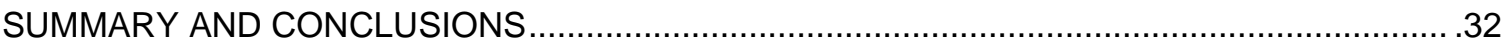

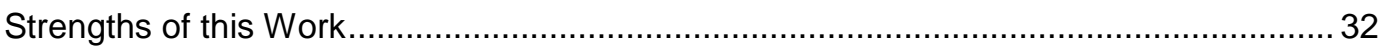

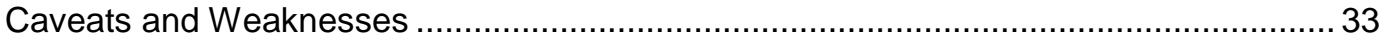

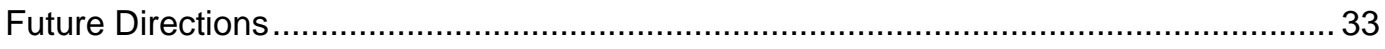

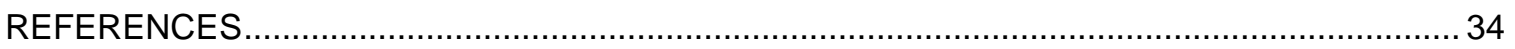

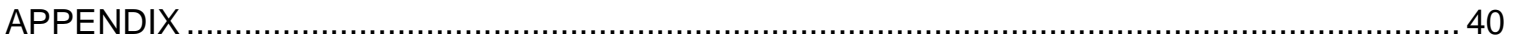

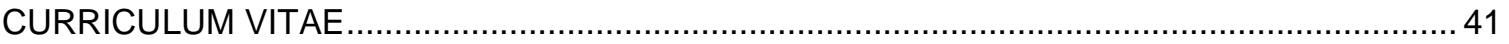




\section{LIST OF FIGURES}

FIGURE

PAGE

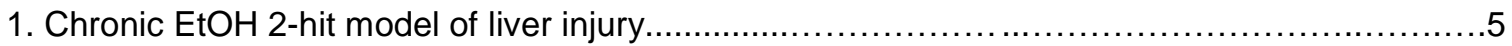

2. Scheme of transitional ECM changes and extraction methodology .................................... 11

3. Validation of ECM extraction technique with $\mathrm{CCl}_{4}$ model of hepatic fibrosis. ............................ 12

4. Liver extracts have unique protein profiles based on fraction type and experimental group.... 13

5. EtOH and LPS cause dynamic changes in the hepatic matrisome ..................................... 15

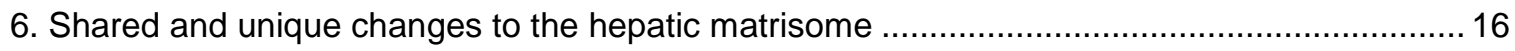

7. Quantitative changes to the hepatic matrisome............................................................. 17

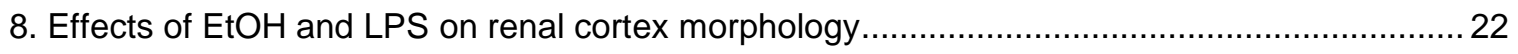

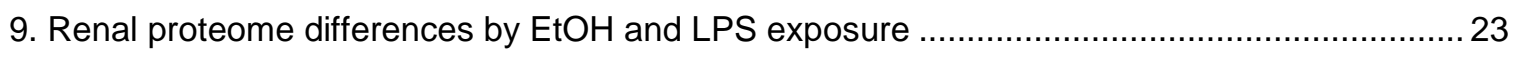

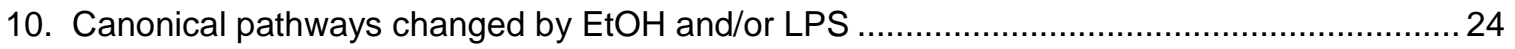

11. Proteins used to predict EtOH-induced deactivation of Nrf2 pathway ................................ 25

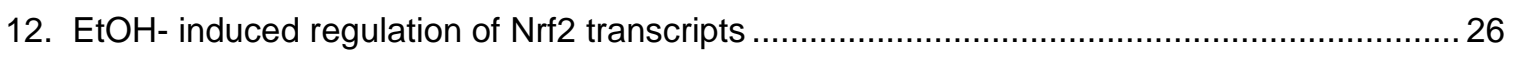

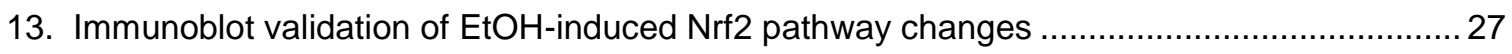




\section{INTRODUCTION}

Although the structural role of the extracellular matrix (ECM) is well known, this compartment contains a diverse range of components that work bi-directionally with surrounding cells to create a dynamic and responsive microenvironment that regulates cell and tissue homeostasis. The ECM components (i.e., 'matrisome') play a key role in signaling via interactions with cell-surface receptors. The ECM also indirectly impacts cell-to-cell communication by binding and retaining soluble mediators including cytokines, chemokines, and growth factors.(1) Proteases and protease inhibitors associated with the ECM also contribute to maintaining its homeostasis, as well as mediating its changes in response to stress or injury.(2)

In some contexts, changes to the ECM are well-recognized and understood; for example, the formation of collagenous scars in tissue is almost a canonical response to unresolved chronic injury. Hepatic fibrosis is a well-known example of this scarring process, (3) as fibrotic livers develop easily detectable collagenous scars. Given the dominance of these changes in the hepatic ECM during fibrogenesis, many studies have focused on the mechanisms that underlie the increases in collagen deposition. However, the alterations of the hepatic ECM during fibrosis are much more diverse than simply an increase in collagen. Indeed fibrosis is characterized by changes in the deposition and distribution of a myriad of other ECM proteins (e.g., laminin and vitronectin).(4) Whereas many of these changes are described, there are still gaps in our understanding.

ECM remodeling is not solely relegated to chronic fibrogenesis, but also contributes to early injury responses in tissue; a well-known example of the latter is the wound healing response. 
The term "transitional tissue remodeling" describes changes to the ECM that do not alter the overall architecture of the organ (Figure 2A). For example, changes in the expression of ECM proteins such as fibronectin (5) and fibrin (6;7) have been observed in models of hepatic inflammation. Importantly, blocking these ECM changes blunts, at least in part, hepatic injury in these models. Therefore, transitional changes to the ECM may contribute to early disease initiation and/or progression prior to the onset of fibrogenesis (Figure 2A). The nature and magnitude of these changes to the ECM are currently poorly understood. A better understanding could elucidate new mechanisms and/or biomarkers for diseases.

Although previous studies have shown that subtle changes in the ECM may contribute to the development of inflammatory liver injury, the research in this area has generally been restricted to study of single ECM proteins (e.g., fibrin)(6;7). A more 'omic approach has been previously hampered by the difficulties associated with the low abundance and insolubility of many ECM proteins. Therefore, a goal of this study was to develop a multi-step liver extraction that would allow for the enrichment and solubilization of ECM proteins. A second goal of this work was to use a proteomic approach to determine global changes in the ECM in models of inflammatory liver damage.

Chronic, heavy ethanol consumption causes kidney damage secondary to hepatic cirrhosis, a phenomenon known as hepato-renal syndrome. Moderate alcohol consumption, however, is currently not considered a risk factor for chronic kidney disease. Furthermore, population based studies have shown moderate alcohol consumption to be inversely associated with kidney injury (8). However, the direct renal effects of chronic moderate EtOH consumption and sensitization to secondary hits are unclear. Rodent studies have identified several mechanisms of alcohol-induced kidney injury that parallel those observed in the liver (9-11). These investigations have been driven by the hypothesis that alcohol affects the kidneys similarly to the liver. It certainly is not surprising that these parallel mechanisms have been confirmed, considering similarities between these two organs, such as the expression of CYP2E1(9).

However, the liver and kidney also have many significant differences in structure, function, and composition. Therefore, it is reasonable to hypothesize that moderate alcohol 
consumption has effects on the kidney that do not parallel mechanisms of hepatotoxicity, especially, perhaps, with respect to alteration of organ response to a second inflammatory stimulus. Efficiently elucidating such unknown mechanisms calls for an unbiased, discoverybased approach. Accordingly, we propose global discovery-based proteomic and transcriptomic investigation of the effects of alcohol preexposure on the response of the renal cortex to lipopolysaccharide (LPS), a prototypical inflammatory stimulus. 


\section{MATERIALS AND METHODS}

\section{Animals and Exposures}

Mice were housed in a pathogen-free barrier facility accredited by the Association for Assessment and Accreditation of Laboratory Animal Care, and procedures were approved by the University of Louisville's Institutional Animal Care and Use Committee. For sacrifice, animals were anesthetized with ketamine/xylazine $(100 / 15 \mathrm{mg} / \mathrm{kg}$, i.p.) and blood was collected from the vena cava just prior to sacrifice. Citrated plasma was stored at $-80^{\circ} \mathrm{C}$ for further analysis and sections of liver and kidney tissue were snap-frozen in liquid nitrogen, frozen-fixed in OCTCompound (Sakura Finetek, Torrance, CA), or were fixed in 10\% neutral buffered formalin for subsequent sectioning and mounting on microscope slides. Paraffin-embedded, formalin fixed samples were stained with Sirius Red/Fast Green to visualize fibrosis $\left(\mathrm{CCl}_{4}\right.$ study)(12). $\underline{\mathrm{CCl}_{4}}$

exposure. Male (4-6 w) C57BL/6J mice were purchased from Jackson Laboratory (Bar Harbor, $\mathrm{ME}$ ). Mice were administered $\mathrm{CCl}_{4}$ (1 ml/kg i.p.; diluted 1:4 in olive oil; Sigma-Aldrich, St. Louis, MO) twice a week for 4 weeks.(12) Ethanol exposure. Male (8 w) C57BL6/J mice were purchased from Jackson Laboratory (Bar Harbor, ME). Mice were fed ethanol-containing Lieber DeCarli diet ad libitum or pair fed isocaloric/isovolumetric maltose-dextrin control diet.(13) EtOH concentrations in the diet were as follows: $0 \%$ for two days, $1 \%$ for two days, $2 \%$ for two days, $4 \%$ for 1 week, $5 \%$ for one week, and $6 \%$ for three weeks. After 6 weeks of feeding, animals were injected with either LPS (E. coli; $10 \mathrm{mg} / \mathrm{kg}$ i.p., Sigma, St. Louis, MO) or vehicle (saline), and euthanized 4 or $24 \mathrm{~h}$ later.(13) (Figure 1).

\section{Hepatic ECM Proteomic Analysis}

Sequential extraction of the hepatic ECM and preparation for LC-MS/MS was performed as 


\section{Figure 1}

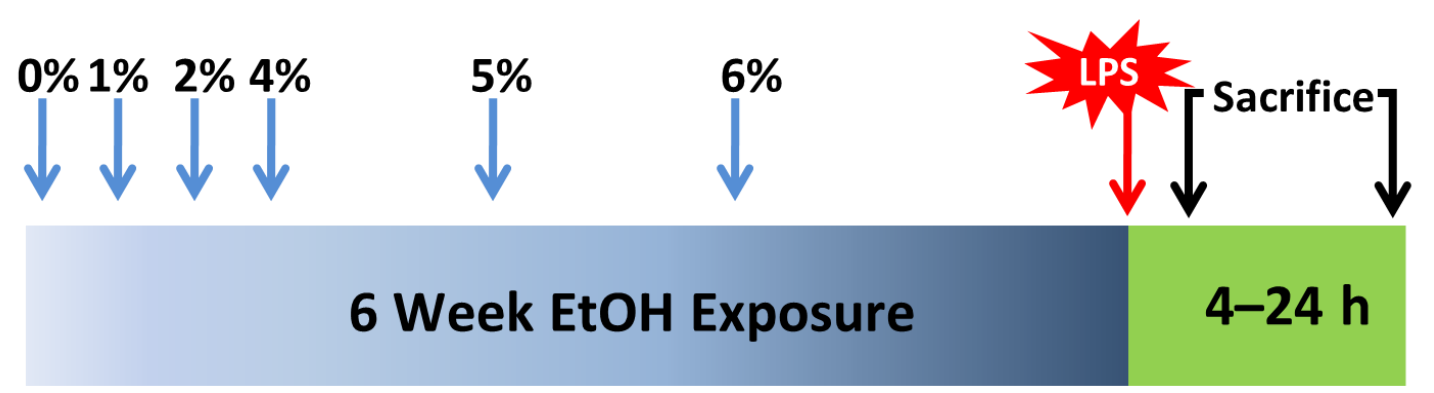

Figure 1: Chronic ethanol 2-hit model of liver injury.

Mice were fed ethanol-containing Lieber DeCarli diet or isocaloric/isovolumetric maltose-dextrin diet for 6 weeks and were injected with LPS (10 mg/kg i.p.) or vehicle (saline) 4 or 24 hours prior to sacrifice. 
described by de Castro Bras et al. for heart tissue,(14) with minor modifications such as not pooling the final solubilized pellet with the $\mathrm{GnHCl}$ fraction(Figure 2).

Samples were separated on Dionex Acclaim PepMap 10075 uM x 2cm nanoViper (C18, $3 \mu \mathrm{m}, 100 \AA)$ trap and Dionex Acclaim PepMap RSLC 50uM x $15 \mathrm{~cm}$ nanoViper (C18, $2 \mu \mathrm{m}, 100 \AA)$ separating columns. An EASY n-LC (Thermo) UHPLC system was used with buffer $A=2 \% \mathrm{v} / \mathrm{v}$ acetonitrile $/ 0.1 \% \mathrm{v} / \mathrm{v}$ formic acid and buffer $\mathrm{B}=80 \% \mathrm{v} / \mathrm{v}$ acetonitrile $/ 0.1 \% \mathrm{v} / \mathrm{v}$ formic acid as mobile phases. A Nanospray Flex source (Thermo) was used to position the end of the emitter near the ion transfer capillary of the mass spectrometer. An Orbitrap Elite - ETD mass spectrometer (Thermo) was used to collect data from the LC eluate. An Nth Order Double Play with ETD Decision Tree method was created in Xcalibur v2.2.

\section{Hepatic ECM Proteomic Data Analysis}

Proteome Discoverer v1.4.0.288 was used to analyze the data collected by the mass spectrometer. The database used in Mascot v2.4 and SequestHT searches was the 6/2/2015 version of the UniprotKB Mus musculus reference proteome canonical and isoform sequences. Carbamidomethylation (+57 on C) was selected as a fixed modification, and Asn->Asp (+1 on N) and Met or Pro oxidation (+16) were selected as variable modifications. A maximum of two missed cleavages were allowed. In order to estimate the false discovery rate, a Target Decoy PSM Validator node was included in the Proteome Discoverer workflow. The results were annotated with mouse gene ontology (GO) information from the Gene Ontology Annotations Database. Additional analysis of extracellular proteins were further categorized into four classes based on their role in the extracellular space as determined by a comprehensive literature search. These four ECM groups include: (1) glycoproteins and proteoglycans, (2) other ECM-associated proteins, (3) proteases and protease inhibitors and (4) collagens. If no record could be found supporting the hypothesis that a protein was associated with the ECM, the protein was placed into (5), other proteins. 


\section{Renal Cortex Proteomic Analysis}

Renal cortex proteins were extracted in lysis buffer (1:1 w/v) containing 10\% glycerol, 50mM HEPES, 100mM KCl, 2mM EDTA, 0.1\% Nonidet p-40 (NP40), 2mM DTT, 10mM NaF, $0.25 \mathrm{mM} \mathrm{NaVO}_{3}$, and protease inhibitors. Samples were placed in a sonication bath for 5 minutes and incubated on ice for 1 hour. Extract was removed from insoluble matter after centrifugation at $12,000 \times \mathrm{g}$ for 30 minutes.

Renal cortical proteins $(100 \mu \mathrm{g})$ were digested using a Filter-Aided Sample Preparation (FASP) protocol developed by Jacek R. Wisniewski, et al. (15) to remove excess SDS detergent used for sample preparation. Proteomic analysis of tissue lysates were conducted as previously described (16) with the following exceptions. Proteins were digested with Lys-c (1:100 w:w rLysC: protein ratio) and trypsin (1:100 w:w trypsin:protein ratio. Peptides were desalted using HLB extraction (Waters Oasis HLB 1cc, WAT094225) as described by Keshishian, et al (17). $50 \mu \mathrm{g}$ peptide were dried and resuspended in $100 \mu \mathrm{L} 100 \mathrm{mM}$ triethylammonium bicarbonate (TEABC). Peptide concentrations were measured using an A205 nm assay with external bradykinin standard curve.

Samples were prepared to a concentration of $0.5 \mu \mathrm{g} / \mu \mathrm{L}$ in $100 \mathrm{mM}$ TEABC. Tandem mass tag (TMT) 10-plex labeling (Thermo 90111) was carried out according to manufacturer's instructions using $50 \mu \mathrm{g}$ peptide per label tube. Labeled samples were admixed and stored at -80

${ }^{\circ} \mathrm{C}$. Samples were then dried and resuspended in $800 \mu \mathrm{L} 0.1 \% \mathrm{v} / \mathrm{v}$ formic acid. Peptides underwent HLB extraction as described above. HLB eluates were dried and resuspended in $100 \mu \mathrm{L} 2 \% \mathrm{v} / \mathrm{v}$ acetonitrile $0.1 \% \mathrm{v} / \mathrm{v}$ formic acid. Peptide concentrations were measured as described above.

$200 \mu \mathrm{g}$ peptide were fractionated by strong cation exchange using 30-300 $\mu$ g capacity SCX MacroSpin Columns (SMM HIL-SCX.25, the Nest Group, Inc. Southborough, MA, USA) according to manufacturer's instructions. Sample cleanup was performed using C18 PROTO, $300 \AA$ Altra Microspin Columns (the Nest Group, Inc., Southborough, MA, USA). 1D-LCMS 
analysis was carried out using a Proxeon EASY-nLC 1000 UHPLC and nanoelectrospray ionization into an Orbitrap Elite mass spectrometer (Thermo).

\section{Renal Cortex Proteomic Data Analysis}

Mass spectrometry data were analyzed using Proteome Discoverer v1.4.0.288 and Scaffold Q+S v4.3.2. The database used in Mascot v2.4 and SequestHT searches was the 6/2/2014 version of the UniprotKB Mus musculus reference proteome canonical and isoform sequences. In order to estimate the false discovery rate, a Target Decoy PSM Validator node was included in the Proteome Discoverer workflow. A Reporter lons Quantifier node was included for quantification of the TMT reporter ions. TMT purity correction factors were obtained from the manufacturer. The resulting .msf files from Proteome Discoverer were loaded into Scaffold. Intensity based normalization of reporter ions was done using the mean calculation type, modeled on unique peptides, and using an average protein reference. Scaffold was used to calculate the false discovery rate using the Peptide and Protein Prophet algorithms. Data were filtered by Benjamini-Hochberg $(\mathrm{BH})$ corrected ANOVA $p$-value $<0.05$ and fold change $(F C) \geq 1.2$. Ingenuity Pathways Analysis (IPA) was used to identify pathways changed by EtOH, LPS, and/or the combination.

\section{Renal Cortex RNA Seq Analysis}

Snap frozen renal cortex sections were stored at $-80^{\circ} \mathrm{C}$. Samples were placed in RNAlater-ICE (Life Technologies, Carlsbad, CA) and incubated at $-20^{\circ} \mathrm{C}$ for 72 hours prior to RNA extraction. RNA was isolated using the mirVana kit (Life Technologies, Carlsbad, CA) according to manufacturer's instructions for total RNA isolation. RNA quality was evaluated by Nanodrop ND-1000 (Thermo Fisher Scientific, Grand Island, NY) and Agilent 2100 Bioanalyzer (Agilent, Santa Clara, CA) analysis. Ribosomal depletion was carried out prior to RNA seq analysis. RNA libraries were prepared using the TruSe Stranded Total RNA LT sample preparation Kit- Set A with Ribo-Zero Gold. Sequencing was performed on the University of 
Louisville Center for Genetics and Molecular Medicine's (CGeMM) Illumina NextSeq 500/550 75 cycle High Output Kit v2.

RNA Seq data were analyzed using the Tuxedo suite data analysis pipeline.

Differentially expressed transcripts were identified by filtering by ANOVA $p$-value cutoff $(p<0.05)$, a more stringent $\mathrm{BH} q$-value cutoff $(\mathrm{q}<0.01)$ and fold change cutoff of 1.2.

\section{Renal Cortex Immunoblots, Immunohistochemistry, and Catalase Activity Assay}

Immunoblots were carried out as described previously (16) using primary antibodies

against NQO1 (Abcam ab80588), SOD1 (Santa Cruz sc11407), GCLC (ү-GCSc, Santa Cruz sc22755), and catalase (Cell Signaling D5N7V).

Immunohistochemistry was carried out using primary antibodies against fibronectin

(Santa Cruz sc-8422) and catalase (Cell Signaling D5N7V).

Catalase activity in $0.8 \mu \mathrm{g}$ renal cortex lysate was measured based on metabolism of methanol using the Cayman Catalase Assay Kit (\#707002) according to manufacturer's instructions. 


\section{RESULTS}

\section{Analysis of changes to the ECM proteome caused by $\mathrm{CCl}_{4}$-induced hepatic fibrosis.}

Previous studies have investigated the matrisome profile for aortic vessel and cardiac tissue $(14 ; 18)$. However, this method has never been employed for liver tissue. The first goal of this work was therefore to validate this approach for hepatic tissue in a model that causes robust changes to the hepatic ECM (i.e., fibrosis). Specifically, the impact of 4 weeks $\mathrm{CCl}_{4}$ exposure (see Methods) on the ECM proteome was determined (Figure 3). As expected (12), $\mathrm{CCl}_{4}$ exposure caused robust ECM deposition that was easily detected with standard collagen stains (Sirius Red/Fast Green; Figure 3A) and immunoblotting (Figure 3B). A similar increase in collagen $1 \alpha 1$ was detected via LC-MS/MS (Figure $3 \mathrm{C}$ ). Exposure to $\mathrm{CCl}_{4}$ increased the levels of collagens type III, IV, and V (Figure 3C). However, analysis showed only minor qualitative changes in the ECM proteome in $\mathrm{CCl}_{4}$ exposure when the fractions were informatically collapsed. When the fractions were collapsed, $\mathrm{CCl}_{4}$ exposure increased the number of proteins associated with the ECM by 7 , and only 1 protein was lost compared to the control group (data not shown).

\section{Ethanol and LPS exposure cause global changes to the hepatic matrisome.}

Standard proteomic analysis generally employs a direct analysis of total protein in the absence of additional fractionation steps. To simulate this, the fractions were artificially collapsed post hoc, and quantitative changes in the ECM proteome between the four exposure groups ( \pm Ethanol diet, $\pm 24 \mathrm{~h}$ LPS injection) were compared in a heatmap (Figure $4 \mathrm{~A}$ ); the most upregulated or downregulated ECM proteins normalized to control were used to compare the

groups. Heatmap visualization of the ECM proteomic spectra showed distinct segregation 


\section{Figure 2}

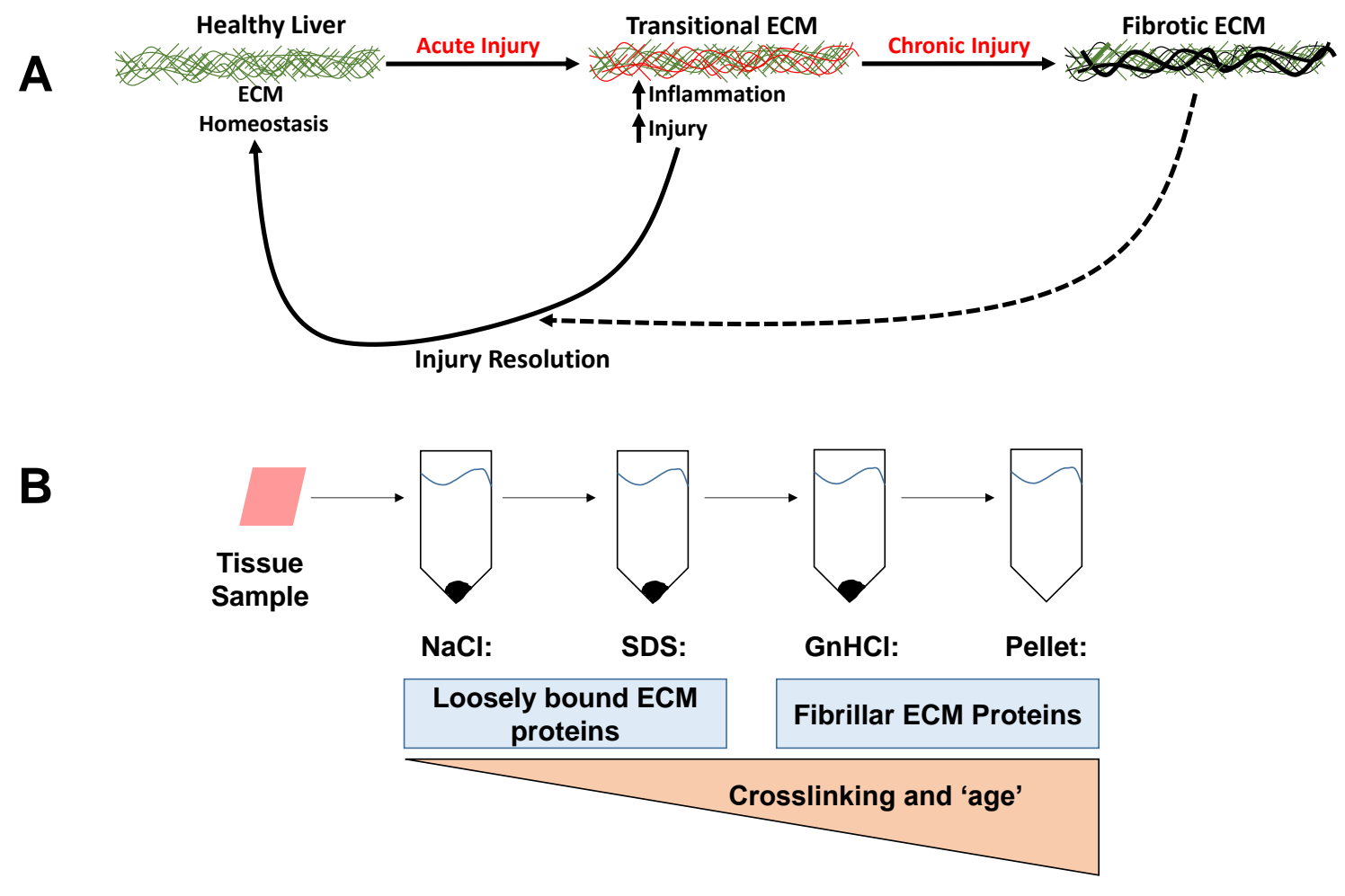

Figure 2: Scheme of transitional ECM changes and extraction methodology. Remodeling in response to chronic injury (i.e., fibrosis) is well-known; however the hepatic extracellular matrix (ECM) also responds dynamically to acute stress. These acute responses can be viewed as an arm of the wound healing response and facilitate recovery from damage, which resolves once the damage is repaired. However, under conditions of chronic injury, these changes contribute to activation of significant remodeling that leads to scar formation (i.e., fibrosis). 
Figure 3

A
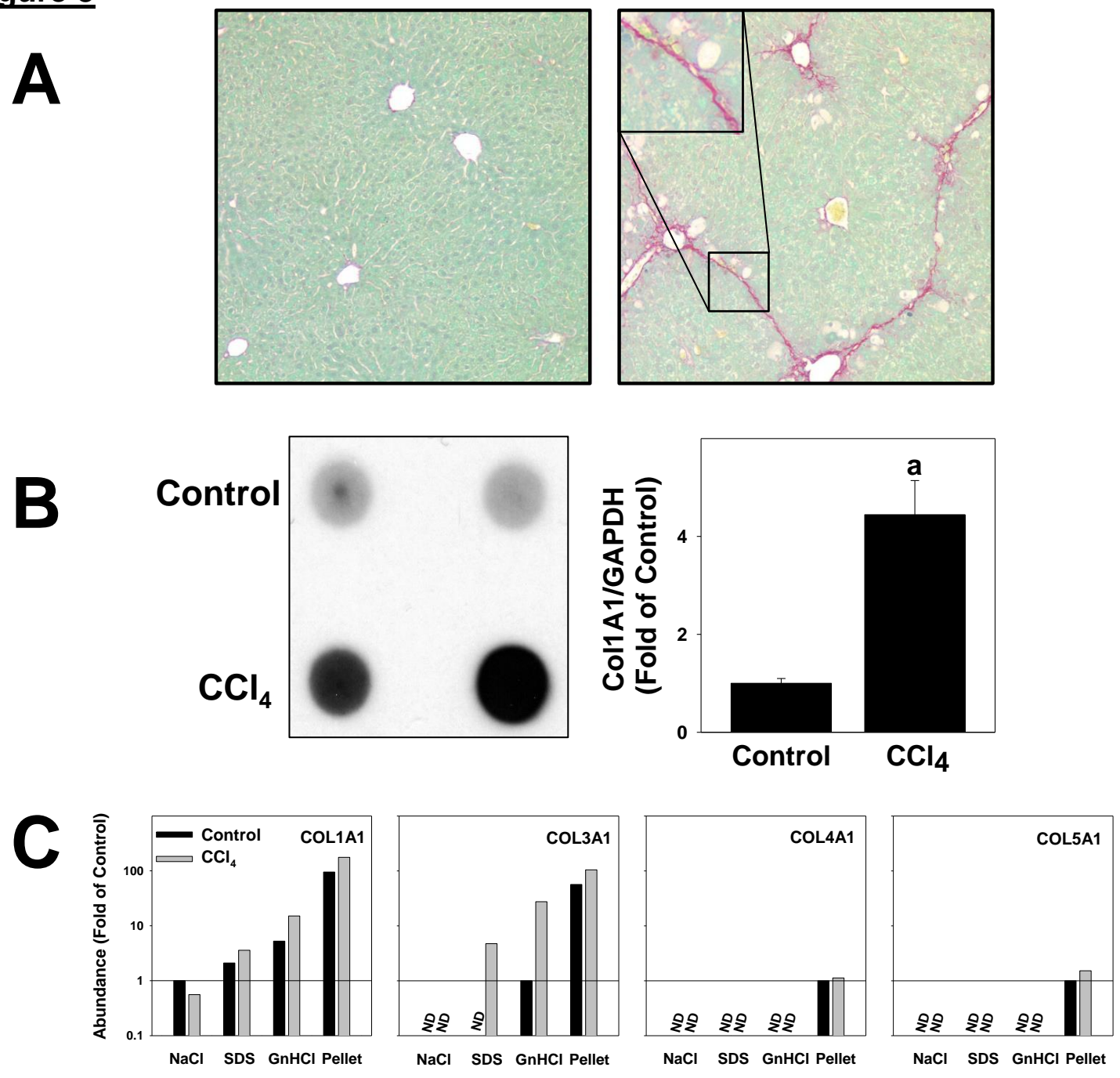

Figure 3: Validation of ECM extraction technique with $\mathrm{CCl}_{4}$ model of hepatic fibrosis.

Animals were administered $\mathrm{CCl}_{4}$ or vehicle for 4 weeks. Collagen type I accumulation was determined by Sirius Red staining (Panel A) and by dot blot (Panel B). Quantitative changes in other collagens was also determined in the ECM extraction fractions (Panel $\mathrm{C}$ ). 


\section{Figure 4}

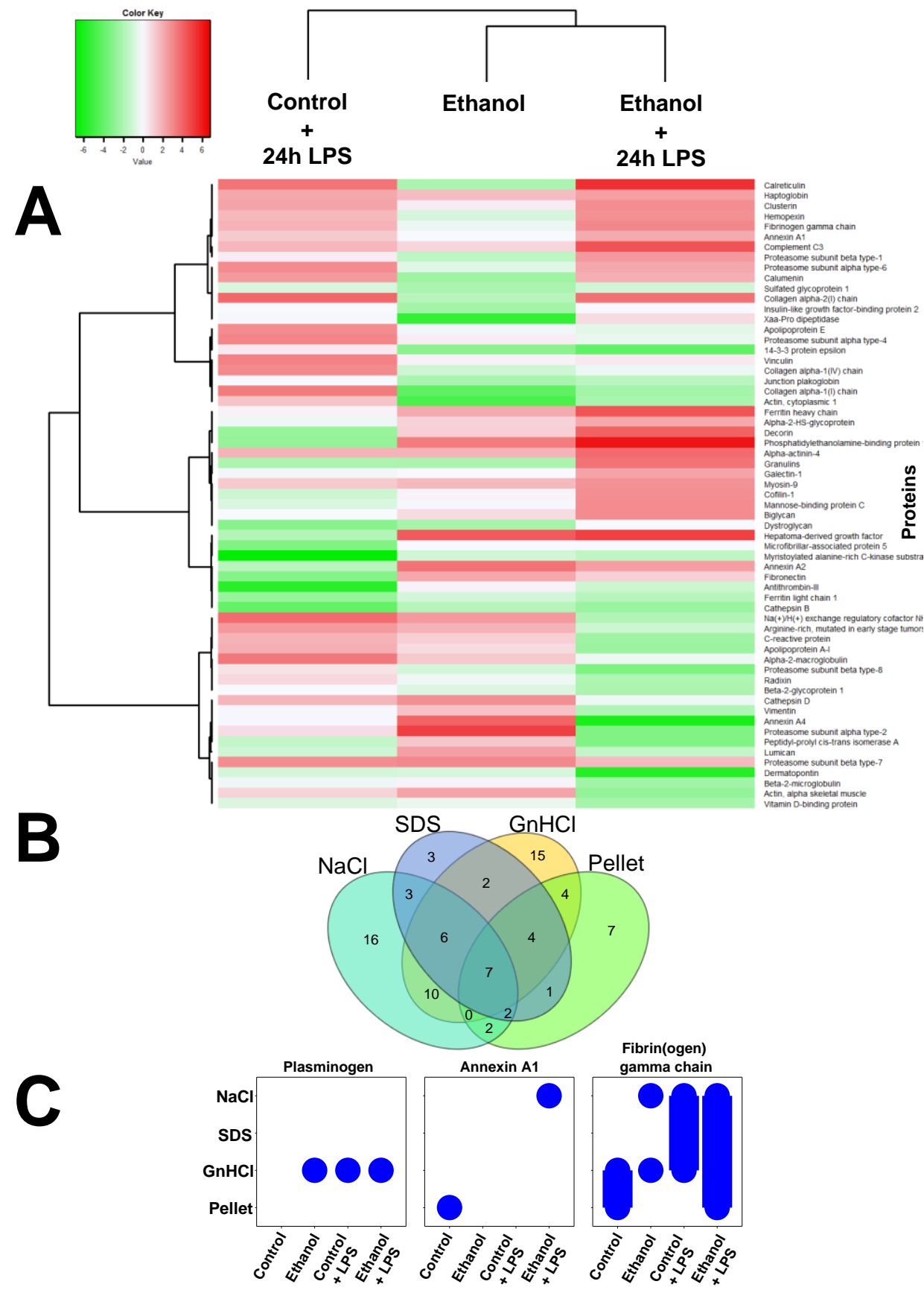

Figure 4: Liver extracts have unique protein profiles based on fraction type and experimental group.

A heatmap depicting quantitative changes to the total ECM proteome in response to ethanol and/or 24h LPS compared to control is shown in Panel A. The number of proteins unique to or shared by all four extractions of control animals is shown (Panel B). Bubble graphs are used to show presence of plasminogen, annexin A1 and fibrin(ogen) gamma chain across the four extracts ( $x$-axis) and the four experimental groups (y-axis) (Panel C). 
between the control group and exposure groups, with ethanol and LPS exposure groups producing varying patterns and the combination of the ethanol/LPS producing shared patterns similar to both exposures alone, but also demonstrated unique patterns (Figure 4A). However, similar to the results with samples from $\mathrm{CCl}_{4}$ (Figure 3), there were few proteins that changed qualitatively in response to ethanol and/or LPS.

\section{3-step serial extraction creates distinct protein profiles.}

ECM proteins are not only regulated at the level of de novo synthesis, but at the level enzymatic activation, degradation and crosslinking. Previous studies have employed a 3-step ECM purification method (Figure 2) in other organs and that approach was adapted for use with liver tissue here.(14;18) The $\mathrm{NaCl}$ extraction displaces polyionic interactions between proteins, thereby solubilizing loosely-bound proteins.(19) Following $\mathrm{NaCl}$ extraction, the remaining liver tissue was decellularized using 1\% SDS. SDS solubilizes cytoplasmic and nuclear membranes, allowing for the release of cellular proteins. Decellularization was followed by a denaturing step with $4 \mathrm{M}$ guanidine $\mathrm{HCl}(\mathrm{GnHCl})$ buffer.(20) Following the denaturing extraction, an insoluble pellet enriched in heavily cross-linked matrix proteins remained.(18) Analysis of the extractions of the $\mathrm{CCl}_{4}$ samples for collagen isoforms (Figure $3 \mathrm{C}$ ) indicated that, as expected, these proteins tended to accumulate in the later extraction fractions. The separation of ECM proteins into each of the four extracts in livers from control animals were qualitatively compared (Figure 4B). Each extract yielded a distinct ECM protein profile consisting of not only ECM proteins that were shared among all four extracts, but also proteins unique to particular extracts (Figure 4B). These results indicate that the extraction approach was effective at separating ECM proteins.

When ECM proteins were compared between experimental groups, interesting patterns of accumulation in the extracts were revealed (Figure 4C). For example, some proteins (e.g., plasminogen) changed in overall "presence" or "absence" in response to exposures but localized consistently to the same fraction when present. Other proteins exhibited more complex responses, also changing in fractionation pattern. For example, whereas annexin A1 was found in the insoluble pellet from control animals, it was not detected in any fraction from animals 


\section{Figure 5}

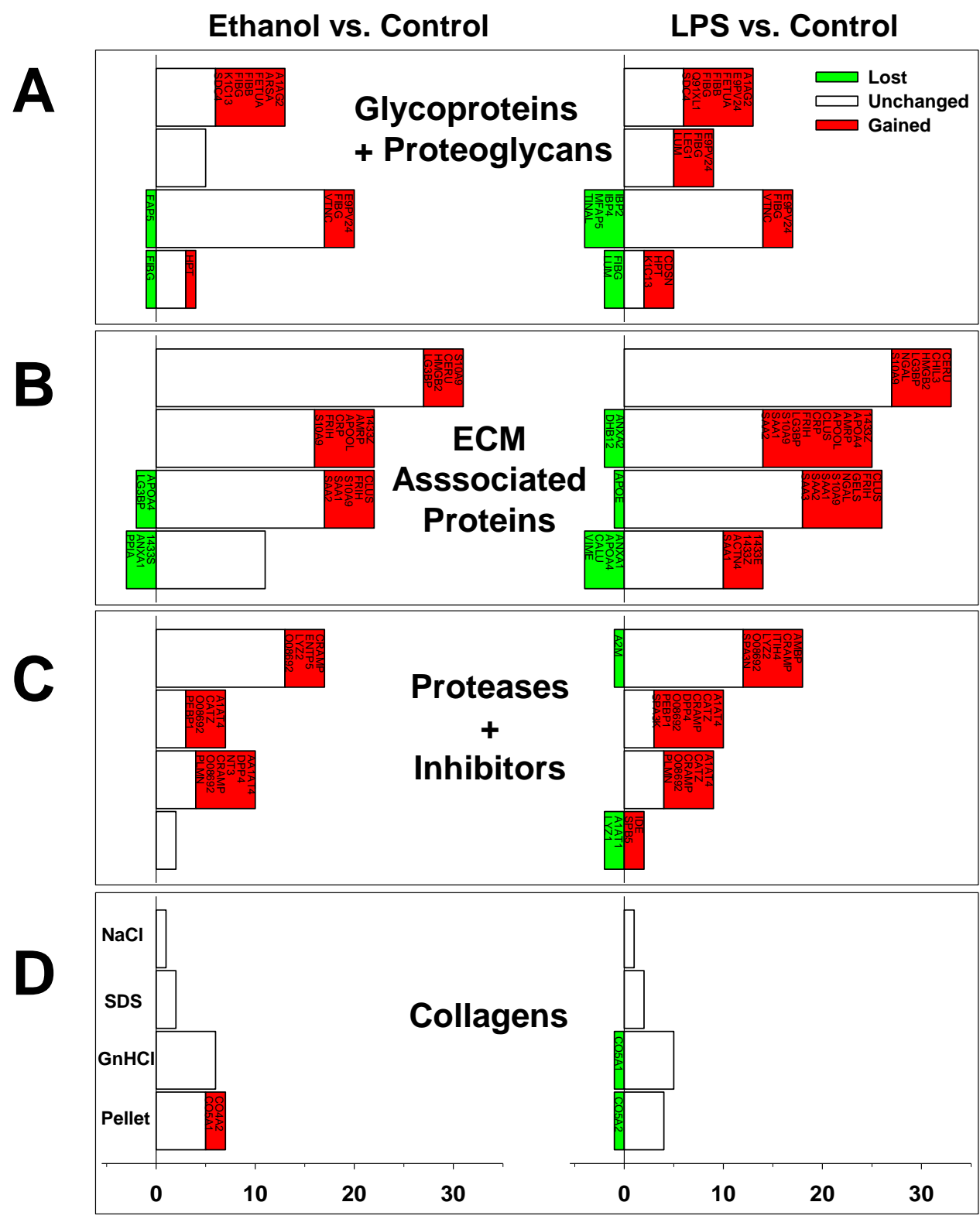

\section{Proteins}

Figure 5: Ethanol and LPS cause dynamic changes in the hepatic matrisome.

The impact of ethanol diet (left panels) and $24 \mathrm{~h}$ LPS (right panels) on the types of proteins found in the ECM proteome are shown. Proteins are categorized by class (Panels A-D) and organized by extraction fraction ( $\mathrm{NaCl}, \mathrm{SDS}, \mathrm{GnHCl}$ and pellet). Red bars indicate proteins that appeared with exposure, while green bars indicate those that were lost with exposure, compared to control. 


\section{Figure 6}

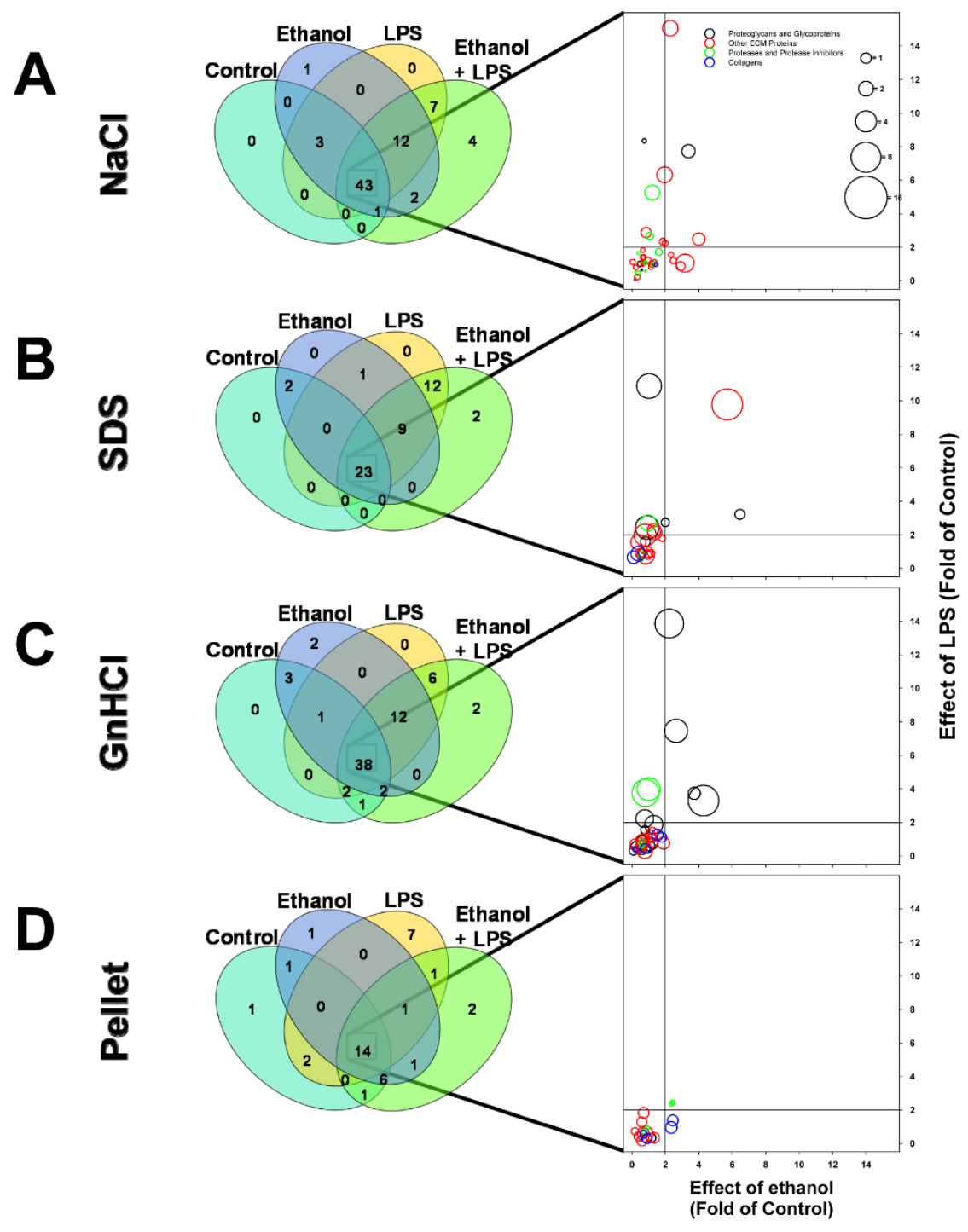

Figure 6: Shared and unique changes to the hepatic matrisome.

Venn diagrams (left column) show all proteins within an extract and indicate the number that are shared between or that are unique to the four experimental groups. Bubble plots (right column) show quantitative changes in abundance of proteins that were shared by all four experimental groups. The bubble plots show fold change in protein expression caused by LPS (y-axis), ethanol (x-axis), and the combination of ethanol + LPS (bubble size). Each bubble represents a single extracellular protein; bubble color indicates the protein's class. 


\section{Figure 7}
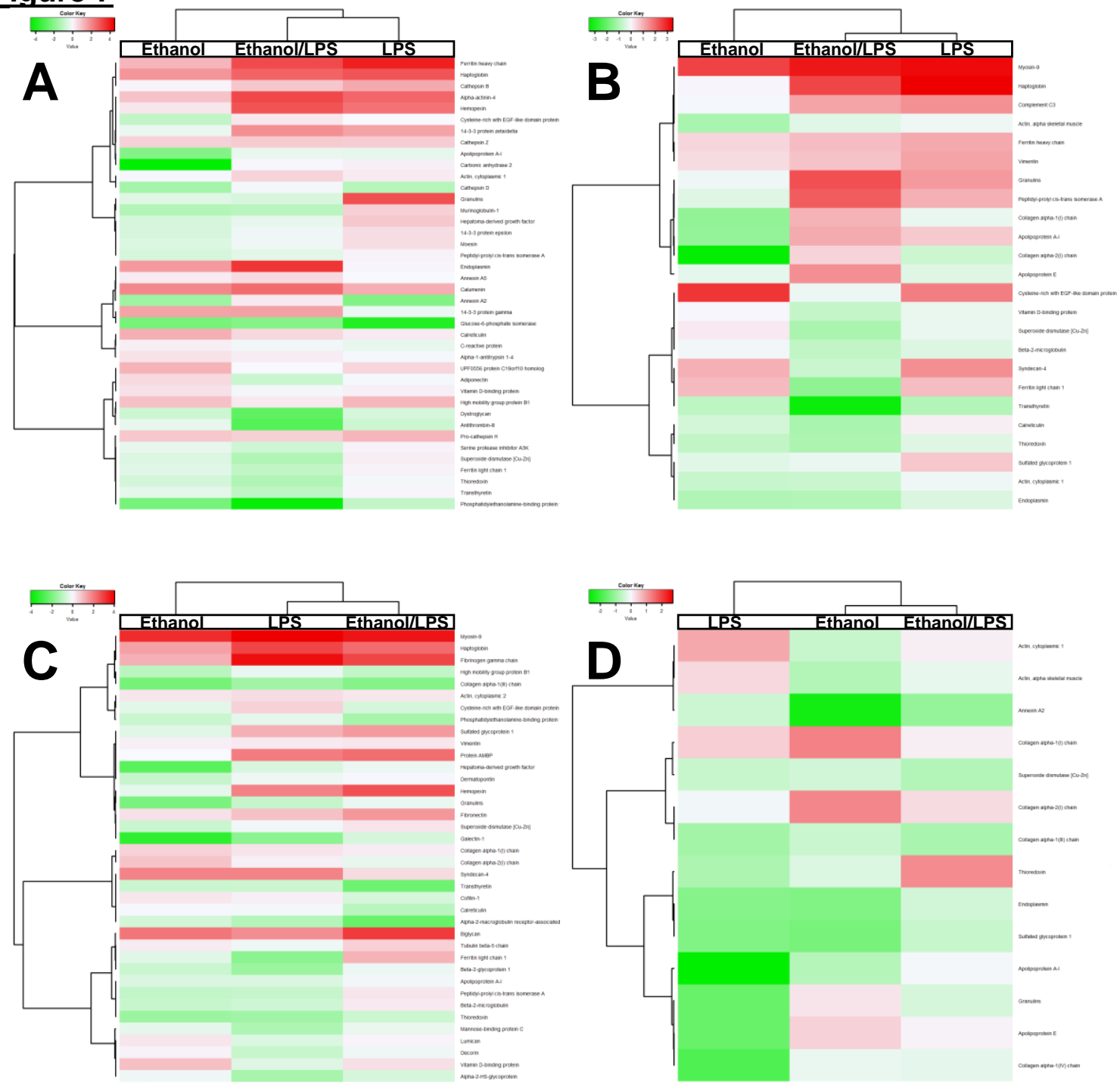

Figure 7: Quantitative changes to the hepatic matrisome.

Heatmap analysis of the quantitative changes in abundance of proteins that were shared by all four experimental groups (See Figure 6) are shown for the $\mathrm{NaCl}$ (panel A), SDS (panel B), GnHCl (panel C) and pellet (panel D) extraction fractions. 
exposed to ethanol or LPS alone; however, the combination of ethanol and LPS caused this protein to accumulate in the $\mathrm{NaCl}$ fraction. Similarly, fibrin(ogen) gamma chain was found in all treatment groups, but its fractionation pattern was unique to each exposure condition. These patterns likely represent differences in the synthesis, degradation and/or maturity of the ECM proteins.

\section{Qualitative changes to the hepatic ECM proteome in response to stress}

Figure 5 summarizes the abundance of proteins, organized by category (i.e., glycoproteins and proteoglycans, ECM associated proteins, proteases and inhibitors and collagens) across the 4 extraction conditions based on Naba et al. (21)or other sources. The majority of the proteins in the $\mathrm{NaCl}$ and $\mathrm{SDS}$ extracts were ECM-associated proteins (class 2; Figure 5B); this was expected, as these are generally loosely associated with the extracellular matrix and are easily solubilized. Additionally, the low abundance of collagens in the $\mathrm{NaCl}$ and SDS fractions (Figure 5D) was not surprising, as collagens are often tightly cross-linked and require denaturing conditions for solubilization. As expected, the denaturing conditions created by $\mathrm{GnHCl}$ more than doubled the number of proteoglycans and glycoproteins in the $\mathrm{GnHCl}$ extract compared to the $\mathrm{NaCl}$ and SDS fractions. The number of collagens in the $\mathrm{GnHCl}$ extract was also dramatically increased compared to the $\mathrm{NaCl}$ and SDS fractions. The pellet fraction contained the fewest proteins of all four extracts; this fraction has the greatest number of collagens.

Ethanol and LPS, alone or combined, did not change the general pattern of proteins found in the various extracts (Figure 5), but both tended to increase the total number of ECM proteins in the fractions combined. For example, ethanol exposure caused a net increase in the number of ECM proteins by $\sim 25 \%$. These changes were predominantly spread across the first 3 protein classes with the $\mathrm{NaCl}, \mathrm{SDS}$ and $\mathrm{GnHCl}$ extracts all increasing to a similar extent. The least responsive protein class were the collagens (Figure 5D). Likewise, the pellet fraction responded the least dynamically to ethanol or LPS exposure and actually showed a net loss in total proteins. Figure 6 (left panels), shows the distribution of the proteins in the various extracts between all 4 exposure groups. 
In addition to proteins that changed in their extraction pattern in response to ethanol (e.g., see Figure 4C), there were several proteins whose presence was unique to ethanol exposure compared to control (Figures 5 and 6); these include fibrin(ogen) $\alpha$ and $\beta$ chains, cytokeratin 13 , vitronectin, plasminogen, high mobility group protein $\mathrm{B} 2$, and collagens IV $\alpha 2$ and Va2. Likewise, LPS exposure caused the appearance of several proteins that were unique compared to control (Figures 5 and 6). Several of these proteins were shared with ethanol exposure, but there were also several that were unique, including serpine B5 (maspin), serine protease inhibitor A3N (Serpin A3N), and CXC motif chemokine 9 (CXCL9) (Figure 6).

Previous work has shown that ethanol pre-exposure sensitizes the liver to inflammatory injury caused by a second insult (i.e. LPS) (22;23). Furthermore, previous studies have suggested that changes in the ECM composition can contribute to the sensitizing effect of ethanol pre-exposure(6). In this study, the combination of chronic ethanol exposure and a second hit of LPS caused unique changes in the ECM protein profile of the liver. The combination of EtOH + LPS resulted in the appearance of 4 unique proteins that were not present in livers from animals exposed to either ethanol or LPS alone, including serum amyloid P and serpine B9.

\section{Quantitative changes to the hepatic ECM proteome caused by stress.}

Dramatic changes to the ECM (i.e., "lost" or "gained") can significantly impact overall organ function; it is not surprising that the majority of the matrisome did not change at the qualitative level. However, several of these proteins did change in relative abundance in response to ethanol and/or LPS (Figures 6 and 7). According to clustering analysis (data not shown) of each fraction, six clusters were identified as the best visual representation of the data. Notable ( $>4$-fold increase) changes caused by LPS included ferritin heavy chain (15-fold increase) in the $\mathrm{NaCl}$ fraction, haptoglobin and myosin-9 (11- and 9-fold, respectively) in the SDS fraction, and fibrinogen y chain and haptoglobin (14- and 7-fold, respectively) in the $\mathrm{GnHCl}$ fraction. Likewise, ethanol exposure changed the abundance of several proteins, including myosin- 9 (6-fold) and

cysteine-rich with EGF-like domain protein 2 (CREDL2; 6-fold) in the SDS fraction. As was 
observed for qualitative analysis (Figure 5), proteins in the pellet fraction responded the least to ethanol and/or LPS.

In addition to the effects of ethanol and LPS, there were also proteins that responded uniquely to the combination of the 2 exposures. For example, although LPS alone did not change endoplasmin abundance compared to control, and ethanol only increased endoplasmin abundance 3-fold, the combination of ethanol and LPS increased the abundance of this protein 11 -fold in the $\mathrm{NaCl}$ fraction (Figures 5 and 6). A similar effect was seen on granulin abundance in the SDS fraction, which was increased by 5 -fold by ethanol and LPS despite no effect by ethanol alone and only a 2-fold increase by LPS (Figures 5 and 6). Additionally, although both LPS and ethanol alone increased CRELD2 the combination of ethanol + LPS actually decreased the levels in the SDS fraction. In the $\mathrm{GnHCl}$ fraction, proteins that were differentially regulated by the combination of ethanol and LPS include hemopexin and alpha-1-microglobulin/bikunin precursor (AMPB).

\section{EtOH and/or LPS cause little change to renal cortex morphology}

No difference or little histological difference was seen in renal cortexes from mice exposed to EtOH, LPS, or the combination, as shown by periodic acid-Schiff (PAS) stain (Figure 8). Cortexes from EtOH fed mice had no detectable differences (Figure 8A). Cortexes from mice injected with LPS after EtOH or pair feeding had minor polymorphonuclear leukocyte infiltration in the interstitial and glomerular space as well as tubular dilation, increased vacuolization, and tubular brush border loss (Figure 8B).

\section{EtOH and LPS each cause unique protein abundance patterns in renal cortex}

170 of 1863 proteins were significantly differentially abundant at $F C \geq 1.2$ across groups (Figure 9). Figure 10 shows the top pathways changed by EtOH compared to control, LPS compared to control, EtOH+LPS compared to LPS, and EtOH+LPS compared to EtOH. The NRF2-mediated oxidative stress response canonical pathway was the pathway with the largest predicted directional change caused by $\mathrm{EtOH}$ consumption. The Nrf2 pathway had a negative $\mathrm{z}$ score with EtOH exposure (Figure 10A), which indicates overall pathway deactivation. This z 
score was based on the change of abundance of many Nrf2 pathway-related proteins in a direction opposite what would be expected if the pathway was activated (Table 1). However, $\mathrm{NAD}(\mathrm{P}) \mathrm{H}$ quinone dehydrogenase 1 (NQO-1) abundance changed in an opposite direction, consistent with Nrf2 pathway activation (Table 1). Western blot analysis of Nrf2 target proteins validates proteomic findings (Figure 11), and catalase activity decreased in a similar pattern to the decrease in catalase abundance.

\section{RNA seq data reinforce proteomic findings}

22 transcripts were upregulated and 44 transcripts were downregulated with $\mathrm{EtOH}$ alone at $F C \geq 2$ and q-value $\leq 0.05$ (Data not shown). The majority of the effects, however, were LPSderived, with 1,141 transcripts upregulated and 673 transcripts downregulated with LPS alone at the same level of stringency. Since the proteomic data showed that EtOH caused a significant negative change in the Nrf2-mediated oxidative stress response pathway, a targeted pathways analysis was carried out examining the transcript changes in this pathway caused by EtOH (Table 2). GCLC and SOD1 transcripts were downregulated, just as the corresponding proteins were downregulated. NQO1 was upregulated as the protein was upregulated. Many other members of the Nrf2-mediated oxidative stress pathway were detected in the transcriptomic data, including the Nrf2 transcript itself, which was upregulated. 


\section{Figure 8}

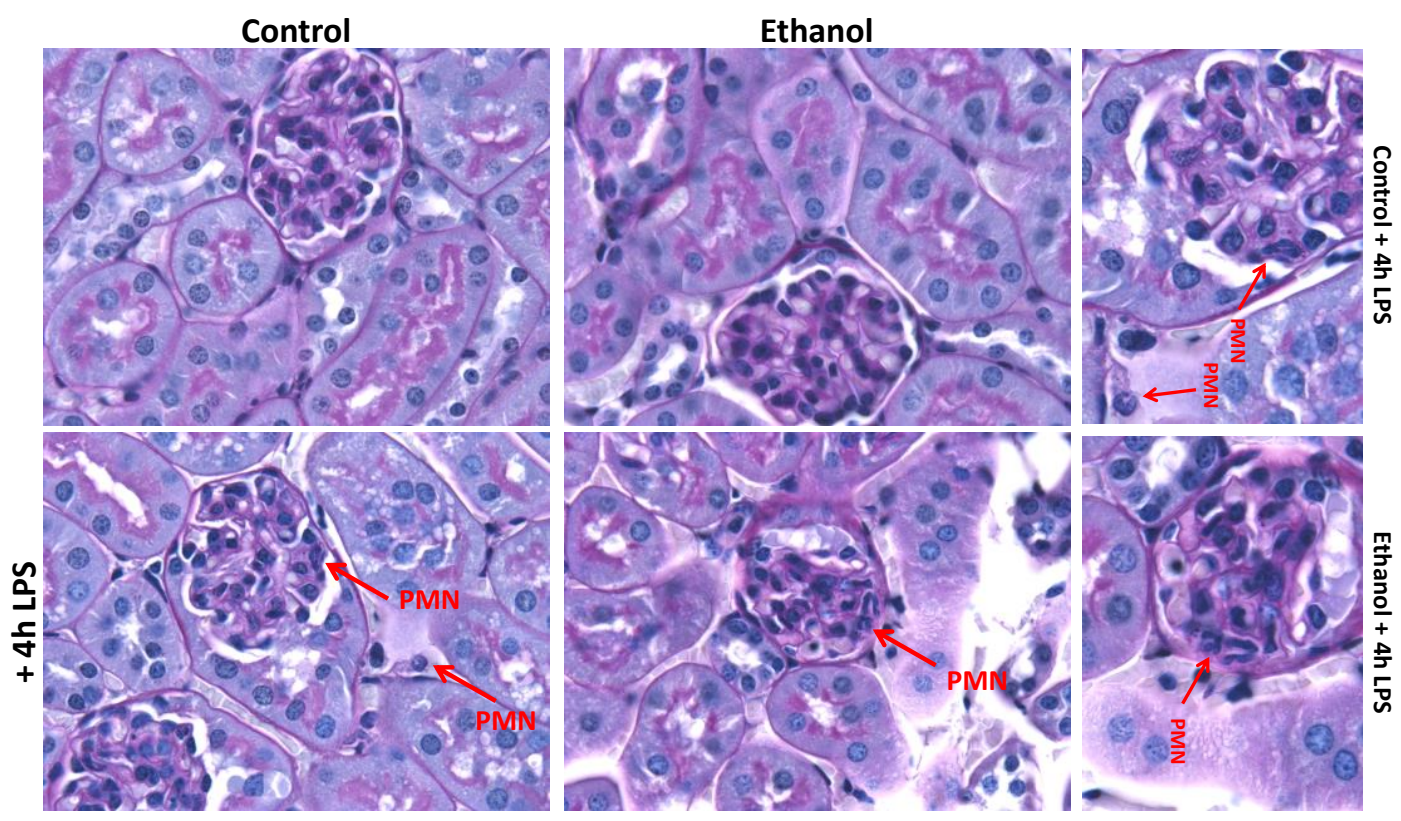

Figure 8: Periodic Acid-Schiff (PAS) staining of renal cortex to evaluate the effects of ethanol and LPS.

PAS staining was carried out on renal cortex tissue from mice exposed to ethanol and/ or 4h LPS. Differences in tubular dilation, vacuolization, tubular brush border loss and polymorphonuclear leukocyte (PMN) infiltration into interstitial and glomerular space are observed for LPS and (LPS+EtOH). 


\section{Figure 9}
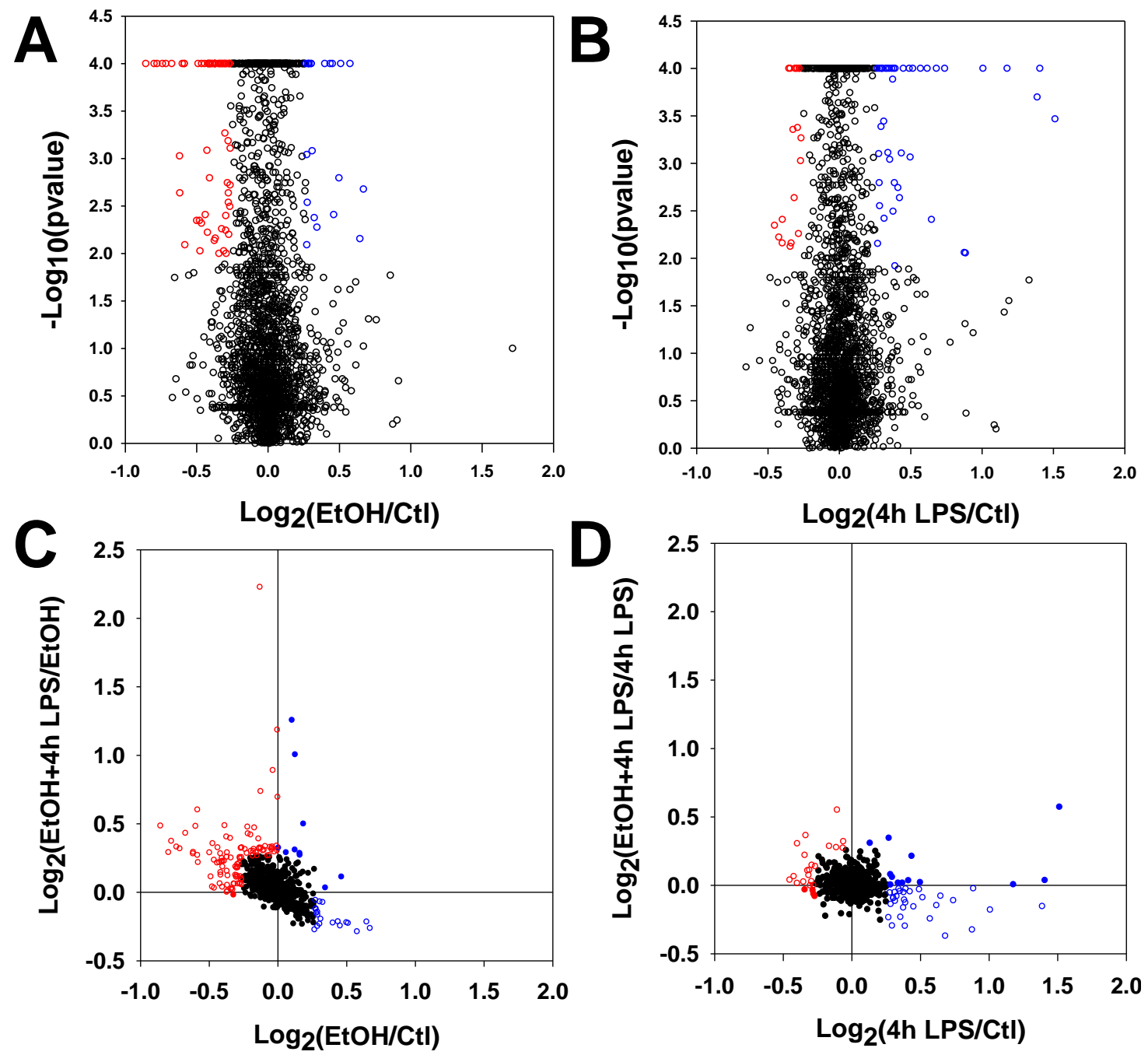

Figure 9: Renal proteome differences by EtOH and LPS exposure.

Protein abundances were estimated with normalized TMT reporter ion data using Scaffold Q+S. Volcano plots were used to filter for large effects of $\mathrm{EtOH}(9 \mathrm{~A})$ and LPS (9B) on protein abundance as primary insults compared to Ctl. A BenjaminiHochberg $(\mathrm{BH})$-corrected $\mathrm{p}$-value of 0.001 and a $\log _{2} \mathrm{FC}$ of 1.2 were used as filters to eliminate proteins from further consideration in emergent properties analysis by Ingenuity Pathways Analysis (IPA). 
Figure 10
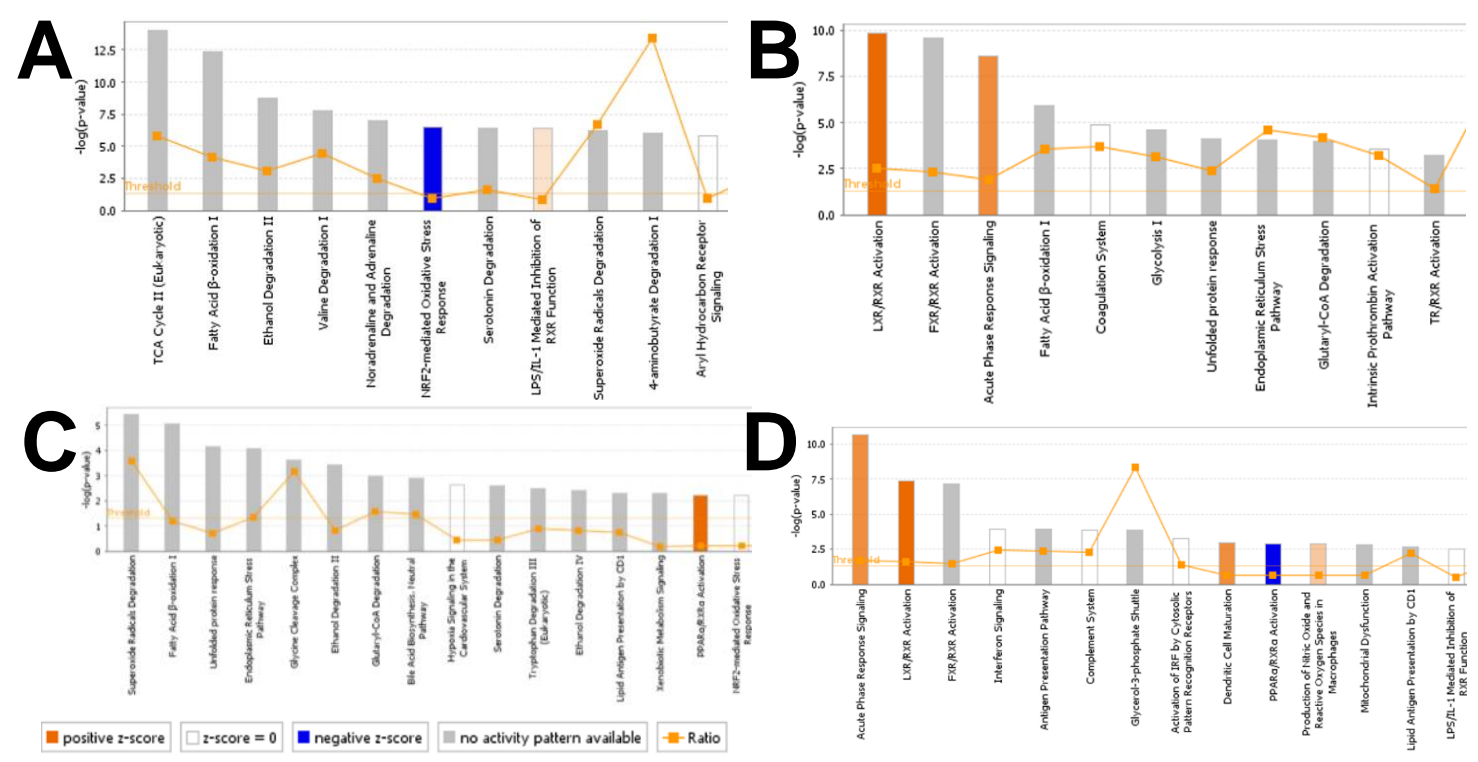

Figure 10: IPA canonical pathways changed by EtOH and/or LPS based on protein fold change (FC).

Gene accessions numbers for significant differentially regulated proteins were analyzed by IPA to determine regulated canonical pathways. Pathways received a z-score based on the direction of the regulation. Canonical pathways changed by ethanol vs. control (10A), 4h LPS vs. control (10B), EtOH+LPS/LPS (10C), and ethanol +4 h LPS vs. ethanol were identified. 


\section{Table 1}

\begin{tabular}{|c|c|c|c|c|c|}
\hline Symbol & Entrez Gene Name & Ensembl & Exp Log Ratio & $\begin{array}{l}\text { Exp FDR (q- } \\
\text { value) }\end{array}$ & Expected \\
\hline ACTB & actin beta & Actb & -0.130 & 7.40E-03 & \\
\hline CAT & catalase & Cat & -0.760 & $9.00 \mathrm{E}-05$ & $\uparrow U p$ \\
\hline CBR1 & carbonyl reductase 1 & Cbr1 & 0.120 & 5.30E-03 & $\uparrow U p$ \\
\hline DNAJC13 & $\begin{array}{l}\text { DnaJ heat shock protein family } \\
\text { (Hsp40) member } \mathrm{C} 13\end{array}$ & Dnajc13 & -0.160 & $6.50 \mathrm{E}-03$ & \\
\hline GCLC & $\begin{array}{l}\text { glutamate-cysteine ligase catalytic } \\
\text { subunit }\end{array}$ & Gclc & -0.240 & 9.00E-05 & $\uparrow U p$ \\
\hline GCLM & $\begin{array}{l}\text { glutamate-cysteine ligase modifier } \\
\text { subunit }\end{array}$ & Gclm & -0.260 & $9.50 \mathrm{E}-03$ & $\uparrow U p$ \\
\hline GSTP1 & glutathione S-transferase pi 1 & Gstp1 & 0.170 & 3.30E-03 & \\
\hline NQO1 & $\begin{array}{l}\text { NAD(P)H quinone dehydrogenase } \\
1\end{array}$ & Nq01 & 0.270 & 9.00E-05 & \\
\hline SOD1 & superoxide dismutase 1 , soluble & Sod1 & -0.480 & 1.70E-03 & \\
\hline SOD2 & $\begin{array}{l}\text { superoxide dismutase } 2 \\
\text { mitochondrial }\end{array}$ & Sod2 & 0.190 & $9.00 \mathrm{E}-05$ & \\
\hline STIP1 & stress induced phosphoprotein 1 & Stip1 & -0.200 & $9.00 \mathrm{E}-05$ & $\uparrow U p$ \\
\hline TXNRD1 $t$ & thioredoxin reductase 1 & Txnrd1 & -0.100 & $3.50 \mathrm{E}-03$ & $\uparrow U p$ \\
\hline
\end{tabular}

Table 1: Proteins used by IPA canonical pathways analysis to predict a selective inactivation of the Nrf2-mediated oxidative stress response pathway with EtOH compared to control.

Ethanol-induced pregulation or downregulation of proteins in the Nrf2-mediated

oxidative stress response pathway contributed to an overall negative z-score assigned by IPA. The "Expected" column contains predicted direction of protein abundance if Nrf2 pathway were activated. Bold indicates protein changes confrimed in western blot studies (Figure 11). 


\section{Table 2}

\begin{tabular}{|c|c|c|c|c|c|}
\hline Symbol & Entrez Gene Name & Ensembl & $\begin{array}{l}\text { Exp Log } \\
\text { Ratio }\end{array}$ & $\begin{array}{l}\text { Exp FDR } \\
\text { (q-value) }\end{array}$ & Expected \\
\hline ABCC4 & $\begin{array}{l}\text { ATP binding cassette } \\
\text { subfamily } \mathrm{C} \text { member } 4\end{array}$ & ENSMUSG00000032849 & 0.658 & $6.88 \mathrm{E}-03$ & $\uparrow U p$ \\
\hline CBR1 & carbonyl reductase 1 & ENSMUSG00000051483 & 0.792 & $6.88 \mathrm{E}-03$ & $\uparrow U p$ \\
\hline DNAJB4 & $\begin{array}{l}\text { DnaJ heat shock } \\
\text { protein family (Hsp40) } \\
\text { member B4 }\end{array}$ & ENSMUSG00000028035 & 0.398 & $5.71 \mathrm{E}-01$ & \\
\hline GCLC & $\begin{array}{l}\text { glutamate-cysteine } \\
\text { ligase catalytic } \\
\text { subunit }\end{array}$ & ENSMUSG00000032350 & -1.386 & 6.88E-03 & $\uparrow U p$ \\
\hline GSTA5 & $\begin{array}{l}\text { glutathione S- } \\
\text { transferase alpha } 5\end{array}$ & ENSMUSG00000074179 & 0.974 & $5.65 E-02$ & \\
\hline HSPB8 & $\begin{array}{l}\text { heat shock protein } \\
\text { family B (small) } \\
\text { member } 8\end{array}$ & ENSMUSG00000041548 & -0.600 & $6.58 \mathrm{E}-01$ & \\
\hline MAF & $\begin{array}{l}\text { MAF bZIP transcription } \\
\text { factor }\end{array}$ & ENSMUSG00000055435 & 0.504 & $1.55 \mathrm{E}-01$ & $\downarrow$ Down \\
\hline MAFF & $\begin{array}{l}\text { MAF bZIP transcription } \\
\text { factor F }\end{array}$ & ENSMUSG00000042622 & -0.812 & 4.25E-01 & $\uparrow U p$ \\
\hline MGST1 & $\begin{array}{l}\text { microsomal glutathione } \\
\text { S-transferase } 1\end{array}$ & ENSMUSG00000008540 & 0.725 & $6.88 \mathrm{E}-03$ & \\
\hline MGST3 & $\begin{array}{l}\text { microsomal glutathione } \\
\text { S-transferase } 3\end{array}$ & ENSMUSG00000026688 & 0.502 & 1.77E-01 & \\
\hline NFE2L2 & $\begin{array}{l}\text { nuclear factor, } \\
\text { erythroid } 2 \text { like } 2\end{array}$ & ENSMUSG00000015839 & 0.339 & $6.50 \mathrm{E}-01$ & $\uparrow U p$ \\
\hline NQ01 & $\begin{array}{l}\text { NAD }(P) H \text { quinone } \\
\text { dehydrogenase } 1\end{array}$ & ENSMUSG00000003849 & 0.398 & 4.16E-01 & \\
\hline PIK3R3 & $\begin{array}{l}\text { phosphoinositide-3- } \\
\text { kinase regulatory } \\
\text { subunit } 3\end{array}$ & ENSMUSG00000028698 & 0.883 & $6.88 \mathrm{E}-03$ & \\
\hline $\begin{array}{l}\text { PMF1/P } \\
\text { MF1- } \\
\text { BGLAP }\end{array}$ & $\begin{array}{l}\text { polyamine-modulated } \\
\text { factor } 1\end{array}$ & ENSMUSG00000028066 & -0.802 & 5.63E-01 & $\uparrow U p$ \\
\hline SOD1 & $\begin{array}{l}\text { superoxide } \\
\text { dismutase } 1 \text {, soluble }\end{array}$ & ENSMUSG00000022982 & -0.364 & 5.04E-01 & \\
\hline SQSTM1 & sequestosome 1 & ENSMUSG00000015837 & -0.520 & 4.66E-01 & $\uparrow U p$ \\
\hline TXN & thioredoxin & ENSMUSG00000028367 & -0.377 & 4.42E-01 & $\uparrow U p$ \\
\hline
\end{tabular}

Table 2: EtOH regulation of Nrf2 transcripts.

Exp Log Ratio- IPA data from RNA-seq results. The "Expected" column contains predicted direction of transcript expression if Nrf2 pathway were activated. Bold indicates proteins used in IB studies (Figure 11). The transcript for Nrf2, NFE2L2, was upregulated in contrast to the downregulation of many Nrf2 target proteins and several of the same Nrf2 target transcripts. 
Figure 11

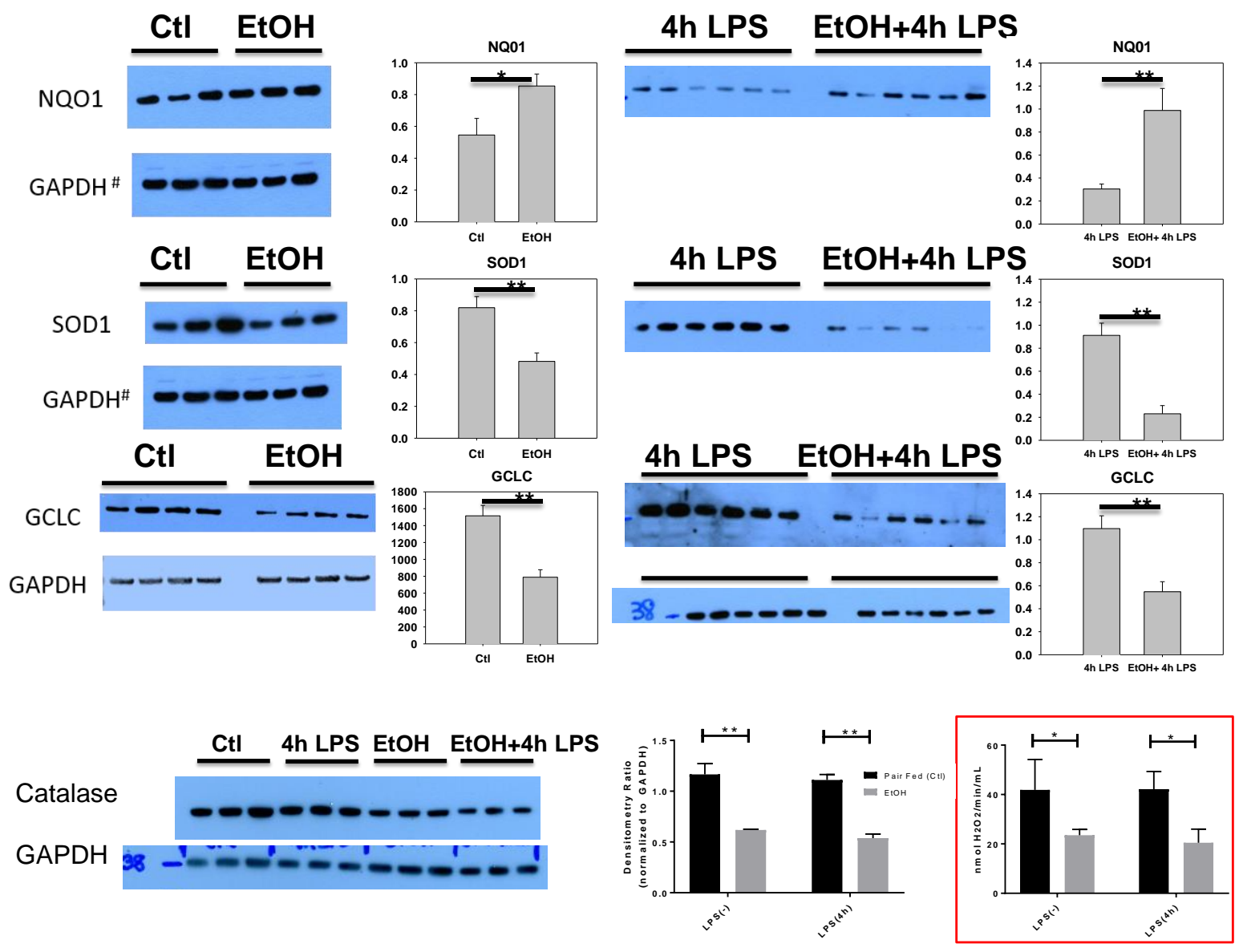

*p-value $<0.05$

$* *$ p-value $<0.01$

Figure 11: Immunoblot validation of EtOH-induced Nrf2 pathway changes. IPA canonical pathways analysis results suggested some Nrf2 gene products were down-regulated with $\mathrm{EtOH}$ exposure in the kidney. Western blot analyses confirm differences as highlighted in Table 1. Differential abundance of Nrf2 target proteins (NQO1 $(n=7)$, SOD1 $(n=7)$, and GCLC $(n=4)$ ) confirmed proteomic observations for both $\mathrm{EtOH}+\mathrm{Ctl}$ and $\mathrm{EtOH}+\mathrm{Ctl}$ plus LPS (4h).

Statistical differences were determined using students t-test or 2-way ANOVA. Catalase activity in renal cortical tissue. Catalase activity was decreased (2way ANOVA, ${ }^{*}=\mathrm{p}$-value $<0.05$ ) in renal cortical tissue of EtOH-fed mice. Catalase activity was not statistically significantly affected by LPS. This pattern of catalase activity is consistent with the IB data for catalase abundance. Activity based on $0.8 \mu \mathrm{g}$ tissue lysate. 


\section{DISCUSSION}

The first aim of this work was to develop and characterize a method of hepatic ECM protein extraction and analysis that would provide both the sensitivity to identify low abundance proteins and the power to observe global changes in the ECM. As mentioned in the Introduction, the study of hepatic ECM proteins has largely been 'collagenocentric' and 'fibrosocentric' - that is, centered on the dramatic increase in collagen deposition during fibrosis, a quasi-permanent scarring of the organ. However, the matrisome of the healthy and diseased liver is significantly more diverse than collagen ECM. Indeed, studies have shown that in addition to collagen, laminin (24) and vitronectin $(25 ; 26)$ are also increased during fibrogenesis. Furthermore, proteomic-based studies in other organs have demonstrated that the matrisome responses dynamically in composition after insult well before fibrotic changes to the organ $(14 ; 18 ; 27)$. Previously, this group has shown that fibrin ECM accumulation correlates with inflammatory liver injury in several models, and may well play a causal role in hepatic damage (6). Additionally, Gillis et al. (5) have shown a similar role for fibronectin ECM in experimental ALD. However, little is known about global changes in the hepatic ECM during inflammatory liver injury.

Global changes in the ECM may mediate tissue function via mechanisms that fall generally into three categories, including physical, biochemical, and signaling mechanisms. Physical properties of the ECM include the matrix topography, organization, and crosslinking (2). These physical properties support the structural role of the ECM, but can also regulate cell migration both by serving as a physical barrier or facilitator to that function (28). Fibrin matrices have been shown to be permissive to chemotaxis and activation of monocytes and leukocytes $(29 ; 30)$. Physical changes in the ECM can cause tissue rigidity resulting in reduced organ function. 
Although such physical changes to the ECM can of course indirectly influence the biochemistry of the liver (e.g., hemostasis-induced hypoxia), changes to the mastrisome can also directly cause biochemical changes that are independent of structural changes. For example, ECM components can facilitate interactions between ligands and receptors (31), bind and retain chemokines (1), and regulate activation of growth factors (i.e. TGF $\beta$ ).(1) ECM molecules can also directly serve as signaling molecules via interactions with cell surface receptors, including integrins.(32) Because of the multi-faceted roles of many ECM molecules, any single change in the ECM can in principle trigger a cascade of dependent changes that influence the composition and properties of the ECM. For example, biglycan serves as a structural component that regulates collagen fiber assembly but upon release from the matrix by can serve as a signaling molecule binding to TLR4 receptors (33).

In the current study, the individual and combined effects of two experimental exposures (ethanol and LPS) on the hepatic matrisome were determined. The rationale for selecting LPS is that it induces a robust inflammatory response in the liver. The liver is often exposed to LPS during several pathophysiologic states, including after alcohol consumption (34). Whereas inflammatory responses triggered by small doses of LPS are typically non-injurious, other stresses can synergistically enhance the hepatotoxic response to LPS. Indeed, in addition to increasing circulating LPS, ethanol also enhances inflammation and liver damage caused by acute LPS exposure (22). This '2-hit' paradigm is a common factor in fatty liver diseases (35). The results here demonstrate that the hepatic matrisome responded dynamically to both stresses, not only increasing the net amount of protein associated with the matrisome, but also differentially changed the amounts (Figure 6) and likely the composition (Figures 5 and 6) of the proteins found.

This study validated changes in the hepatic matrisome that have been reported previously after LPS and/or ethanol exposure. For example, this work validated that the fibrin(ogen) ECM is dramatically altered by LPS and enhanced by the combination of ethanol and LPS(36). In the current study, LPS exposure increased the amount of fibrinogen gamma chain detected in the $\mathrm{GnHCl} \mathrm{extract.} \mathrm{The} \mathrm{fibrin(ogen)} \mathrm{gamma} \mathrm{chain} \mathrm{is} \mathrm{a} \mathrm{major} \mathrm{component} \mathrm{of} \mathrm{fibrin} \mathrm{clots,} \mathrm{as} \mathrm{it} \mathrm{is}$ 
polymerized into insoluble fibrin fibers (37). Therefore, the localization of this robust increase in fibrinogen gamma chain in the $\mathrm{GnHCl}$ fractions suggests that there was an increase in fibrin(ogen) gamma chain polymerization into a less-soluble and more highly cross-linked form. Furthermore, the combination of ethanol and LPS resulted in presence of the fibrin(ogen) gamma chain in the insoluble pellet, which suggests additional modifications that increased insolubility (e.g., crosslinking). The appearance of serum amyloid A-1 and A-2 proteins in response to LPS was also confirmed here $(38 ; 39)$. In fact, LPS administration here increased the detection of several other acute phase proteins, including haptoglobin, complement $\mathrm{C}$, and ceruloplasmin, which are all known to be increased by LPS exposure (40-42). This work validates previous studies with ethanol, which demonstrated increased fibronectin deposition prior to the onset of fibrosis (5).

This technique also identified novel changes caused by ethanol and LPS. For example, vitronectin accumulation has previously been linked to hepatic fibrosis and end-stage liver disease $(43 ; 44)$. The findings of the current study suggest that more subtle changes in vitronectin expression occur prior to the onset of fibrosis and hepatic decompensation. Ethanol exposure also resulted in the appearance of galectin-1. Galectin-1 is glycosaminoglycan-binding lectin associated with cell proliferation and adhesion through modulation of glycoprotein crosslinking. Galectin-1 may also play a role in hepatic inflammation and fibrinogenesis (45). These data suggest that ethanol and/or LPS is likely contributing to a myriad of changes in the ECM composition, many of which have not yet been fully investigated.

Changes in expression of protease and protease inhibitors can also contribute to inflammatory liver injury and fibrogenesis. In the current study, several ECM-associated proteases were increased in response to stress, including plasmin(ogen), antithrombin III, dipeptidyl peptidase, and alpha-1-antitrypsin. Stress also resulted in the presence of protease inhibitors, such as serpine B5 (maspin) and PAl-1. Several other proteases and protease inhibitors that may be critical for ECM homeostasis [e.g., transthyretin, phosphatidylethanolaminbinding protein-1 (PEBP1), and serine protease inhibitor A2K] increased in response to ethanol and/or LPS. These data support the notion that transitional remodeling of the hepatic matrisome 
is likely bidirectional and driven by both increased secretion of matrix proteins as well as changes in ECM degradation.

As mentioned above, ethanol is well-known to synergize liver damage caused by LPS exposure. In the current study, the combination of ethanol and LPS resulted in unique changes to the hepatic matrisome compared to either ethanol or LPS alone. Indeed, fibronectin and biglycan expression were all differentially increase by co-exposure (Figure 4). Fibronectin accumulation caused by ethanol may contribute to hepatic inflammation via stimulation of Kupffer cells (46). Biglycan is a small proteoglycan was first recognized as a structural component and signaling molecule in the ECM (47), but has also been implicated in inflammation (48), potentially by retaining pro-inflammatory cytokines (49) and/or by activating TLR4 signaling (50). These data suggest that biglycan expression may be increased in pre-fibrotic stages of liver disease. In contrast, the combination of ethanol and LPS synergistically decreased phosphatidylethanolamine-binding protein-1 (PEBP1); this enzyme has been shown to inhibit trypsin-like serine proteases including thrombin, but not trypsin or tissue-type plasminogen activator (51). Multiple studies have identified PEBP1 as a critical player in metastasis (52), and have defined it as a metastasis suppressor gene (53). The implications of these changes will be pursued in future studies.

Although chronic moderate alcohol consumption causes steatohepatitis, the effects on the kidney at the tissue level are currently indiscernible, in contrast to subtle changes caused by acute LPS exposure. As such, these results are consistent with population data on the effects of moderate drinking on the kidney (8).

Moderate, chronic alcohol consumption is known to prime other organs such as the liver and the lung for injury following a 'second hit'. IPA results suggests that EtOH, LPS, EtOH+LPS have differential effects on unique protein canonical pathways related to stress response, for example: inactivation of $\mathrm{Nrf2}$ by EtOH or peroxisome proliferator-activated receptor (PPARa)/retinoid $\mathrm{x}$ receptor (RXRa) by LPS and activation of the acute phase response or liver $x$ receptor $(\mathrm{LXR}) / \mathrm{RXR}$ by LPS. 


\section{SUMMARY AND CONCLUSIONS}

\section{STRENGTHS OF THIS WORK}

One overall strength of this work is the use of a discovery-based 'omics approach, which is not limited by the current knowledge based compared to hypothesis-driven approaches.

Additionally, this type of work provides the foundation for many new hypotheses.

In summary, the results demonstrate that the hepatic matrisome responds dynamically to both acute (LPS) and chronic (ethanol) stresses, prior to more dramatic fibrotic changes to the liver. It is likely that these transitional changes to the hepatic ECM contribute to the pathologic responses to these stresses. It is also interesting that several ECM proteins responded similarly to both stresses, suggesting a common mechanism in both models. The changes in proteins that were unique to either exposure alone (or their combination) also represents potential new biomarkers or targets. These results therefore also serve as a foundation for future analyses in hepatic models of liver disease.

This work also demonstrates that although moderate, chronic alcohol consumption does not cause noticeable tissue-level changes in the kidney, alcohol does cause protein-level changes. Most notably, ethanol was shown to dysregulate the Nrf2-mediated oxidative stress response pathway in the renal cortex, whether or not LPS was also administered. The importance of the Nrf2 pathway has been established in many disease states $(54 ; 55 ; 55 ; 56)$, and so this work suggests moderate alcohol consumption may affect Nrf2-related pathologies in the kidney. 


\section{CAVEATS AND WEAKNESSES}

This work used a mouse model of chronic, moderate alcohol consumption. Therefore, the changes identified in both the liver and kidney studies may not necessarily be relevant to binge drinking. However, acute and chronic models of alcohol consumption have great mechanistic overlap, as evidenced by studies of protective agents in both types of models $(57 ; 58)$ The renal cortex proteomic data are limited by the use of whole cortical tissue for discovery proteomics and the use of TMT isobaric labeling reagents which can lead to compression of observed reporter ion

differences. Despite these limitations, we have confirmed multiple observations of the effect of EtOH and LPS on protein abundance.

\section{FUTURE DIRECTIONS}

Future directions for the investigation of the effects $\mathrm{EtOH}$ on the hepatic transitional ECM include determining the critical roles of the identified proteins in $\mathrm{EtOH}$-induced liver injury. Future directions for the investigation of the effects of $\mathrm{EtOH}$ on the renal cortex proteome include determining the role of the proteosome versus autophagy for $\mathrm{EtOH}$ induced loss of catalase and determining the clinical relevance of these $\mathrm{EtOH}$-induced effects on the kidney. 


\section{REFERENCES}

1. Hynes RO. The extracellular matrix: not just pretty fibrils. Science 2009 Nov 27;326(5957):1216-9. PMCID:PMC3536535

2. Lu P, Takai K, Weaver VM, Werb Z. Extracellular matrix degradation and remodeling in development and disease. Cold Spring Harb.Perspect.Biol. 2011 Dec;3(12). PMCID:PMC3225943

3. Friedman SL. Stellate cell activation in alcoholic fibrosis--an overview. Alcohol Clin Exp.Res 1999 May;23(5):904-10

4. Gressner OA, Weiskirchen R, Gressner AM. Evolving concepts of liver fibrogenesis provide new diagnostic and therapeutic options. Comp Hepatol 2007;6:7. PMCID:PMC1994681

5. Gillis SE, Nagy LE. Deposition of cellular fibronectin increases before stellate cell activation in rat liver during ethanol feeding. Alcohol Clin Exp.Res 1997 Aug;21(5):857-61

6. Beier JI, Luyendyk JP, Guo L, von Montfort C, Staunton DE, Arteel GE. Fibrin accumulation plays a critical role in the sensitization to lipopolysaccharide-induced liver injury caused by ethanol in mice. Hepatology. 2009 Jan 23;49(5):1545-53. PMCID:PMC2852109

7. Bergheim I, Guo L, Davis MA, Lambert JC, Beier JI, Duveau I, Luyendyk JP, Roth RA, Arteel GE. Metformin prevents alcohol-induced liver injury in the mouse: Critical role of plasminogen activator inhibitor-1. Gastroenterology. 2006 Jun;130(7):2099-112

8. Koning SH, Gansevoort RT, Mukamal KJ, Rimm EB, Bakker SJ, Joosten MM. Alcohol consumption is inversely associated with the risk of developing chronic kidney disease. Kidney Int 2015 May;87(5):1009-16

9. Harris PS, Roy SR, Coughlan C, Orlicky DJ, Liang Y, Shearn CT, Roede JR, Fritz KS. Chronic ethanol consumption induces mitochondrial protein acetylation and oxidative stress in the kidney. Redox.Biol 2015 Dec;6:33-40. PMCID:PMC4511634

10. Latchoumycandane C, Nagy LE, McIntyre TM. Chronic ethanol ingestion induces oxidative kidney injury through taurine-inhibitable inflammation. Free Radic Biol Med 2014 Apr;69:403-16. PMCID:PMC3960325

11. Latchoumycandane C, Nagy LE, McIntyre TM. Myeloperoxidase formation of PAF receptor ligands induces PAF receptor-dependent kidney injury 
during ethanol consumption. Free Radic Biol Med 2015 Sep;86:179-90. PMCID:PMC4554800

12. von Montfort C, Beier JI, Kaiser JP, Guo L, Joshi-Barve S, Pritchard MT, States JC, Arteel GE. PAI-1 plays a protective role in $\mathrm{CCl} 4$-induced hepatic fibrosis in mice: role of hepatocyte division. Am.J.Physiol Gastrointest.Liver Physiol. 2010 Mar 4;298(5):G657-66. PMCID:PMC2867423

13. Massey VL, Poole LG, Siow DL, Torres E, Warner NL, Schmidt RH, Ritzenthaler JD, Roman J, Arteel GE. Chronic Alcohol Exposure Enhances Lipopolysaccharide-Induced Lung Injury in Mice: Potential Role of Systemic Tumor Necrosis Factor-Alpha. Alcohol Clin.Exp.Res. 2015 Oct;39(10):197888

14. de Castro Bras LE, Ramirez TA, DeLeon-Pennell KY, Chiao YA, Ma Y, Dai Q, Halade GV, Hakala K, Weintraub ST, Lindsey ML. Texas 3-step decellularization protocol: looking at the cardiac extracellular matrix. $\mathrm{J}$ Proteomics. 2013 Jun 28;86:43-52. PMCID:PMC3879953

15. Wisniewski JR, Zougman A, Nagaraj N, Mann M. Universal sample preparation method for proteome analysis. Nat.Methods 2009 May;6(5):35962

16. Rood IM, Merchant ML, Wilkey DW, Zhang T, Zabrouskov V, van d, V, Dijkman HB, Willemsen BK, Wetzels JF, Klein JB, et al. Increased expression of lysosome membrane protein 2 in glomeruli of patients with idiopathic membranous nephropathy. Proteomics. 2015 Nov;15(21):3722-30

17. Keshishian $H$, Burgess MW, Gillette MA, Mertins $P$, Clauser KR, Mani DR, Kuhn EW, Farrell LA, Gerszten RE, Carr SA. Multiplexed, Quantitative Workflow for Sensitive Biomarker Discovery in Plasma Yields Novel Candidates for Early Myocardial Injury. Mol.Cell Proteomics. 2015 Sep;14(9):2375-93. PMCID:PMC4563722

18. Didangelos A, Yin X, Mandal K, Baumert M, Jahangiri M, Mayr M. Proteomics characterization of extracellular space components in the human aorta. Mol.Cell Proteomics. 2010 Sep;9(9):2048-62. PMCID:PMC2938114

19. Mason RM, Mayes RW. Extraction of cartilage protein-polysaccharides with inorganic salt solutions. Biochem.J 1973 Mar;131(3):535-40.

PMCID:PMC1177500

20. Sajdera SW, Hascall VC. Proteinpolysaccharide complex from bovine nasal cartilage. A comparison of low and high shear extraction procedures. J Biol.Chem. 1969 Jan 10;244(1):77-87 
21. Naba A, Clauser KR, Ding H, Whittaker CA, Carr SA, Hynes RO. The extracellular matrix: Tools and insights for the "omics" era. Matrix Biol 2016 Jan;49:10-24. PMCID:PMC5013529

22. Enomoto N, Ikejima K, Bradford BU, Rivera CA, Kono H, Brenner DA, Thurman RG. Alcohol causes both tolerance and sensitization of rat Kupffer cells via mechanisms dependent on endotoxin. Gastroenterology $1998 \mathrm{Jul}$ 24;115(2):443-51

23. Tsukamoto H, Takei Y, McClain CJ, Joshi-Barve S, Hill D, Schmidt J, Deaciuc I, Barve S, Colell A, Garcia-Ruiz C, et al. How Is the Liver Primed or Sensitized for Alcoholic Liver Disease? Alcohol.Clin.Exp.Res. $2001 ; 25(5): 171 S-81 S$

24. Eyre DR, Paz MA, Gallop PM. Cross-linking in collagen and elastin. Annu.Rev.Biochem. 1984;53:717-48

25. Kobayashi J, Yamada S, Kawasaki H. Distribution of vitronectin in plasma and liver tissue: relationship to chronic liver disease. Hepatology 1994 Dec;20(6):1412-7

26. Koukoulis GK, Shen J, Virtanen I, Gould VE. Vitronectin in the cirrhotic liver: an immunomarker of mature fibrosis. Hum.Pathol. 2001 Dec;32(12):1356-62

27. Didangelos A, Yin X, Mandal K, Saje A, Smith A, Xu Q, Jahangiri M, Mayr M. Extracellular matrix composition and remodeling in human abdominal aortic aneurysms: a proteomics approach. Mol.Cell Proteomics. 2011 Aug;10(8):M111. PMCID:PMC3149094

28. Egeblad M, Rasch MG, Weaver VM. Dynamic interplay between the collagen scaffold and tumor evolution. Curr.Opin.Cell Biol. 2010 Oct;22(5):697-706. PMCID:PMC2948601

29. Holdsworth SR, Thomson NM, Glasgow EF, Atkins RC. The effect of defibrination on macrophage participation in rabbit nephrotoxic nephritis: studies using glomerular culture and electronmicroscopy. Clin.Exp.Immunol. 1979 Jul;37(1):38-43

30. Loike JD, el Khoury J, Cao L, Richards CP, Rascoff H, Mandeville JT, Maxfield FR, Silverstein SC. Fibrin regulates neutrophil migration in response to interleukin 8 , leukotriene $\mathrm{B} 4$, tumor necrosis factor, and formylmethionyl-leucyl-phenylalanine. J.Exp.Med. 1995 May 1;181(5):1763-72

31. Lonai P. Epithelial mesenchymal interactions, the ECM and limb development. J Anat. 2003 Jan;202(1):43-50. PMCID:PMC1571048

32. Hynes RO. Integrins: versatility, modulation, and signaling in cell adhesion. Cell. 1992 Apr 3;69(1):11-25 
33. Nastase MV, Young MF, Schaefer L. Biglycan: a multivalent proteoglycan providing structure and signals. J Histochem.Cytochem. 2012 Dec;60(12):963-75. PMCID:PMC3527886

34. Bode $\mathrm{CH}$, Kugler $\mathrm{V}$, Bode $\mathrm{JCH}$. Endotoxemia in patients with alcoholic and non-alcoholic cirrhosis and in subjects with no evidence of chronic liver disease following acute alcohol excess. J.Hepatol. 1987;4:8-14

35. Day CP, James OF. Steatohepatitis: a tale of two "hits"? Gastroenterology. 1998 Apr;114(4):842-5

36. Beier JI, Luyendyk JP, Guo L, von MC, Staunton DE, Arteel GE. Fibrin accumulation plays a critical role in the sensitization to lipopolysaccharideinduced liver injury caused by ethanol in mice. Hepatology 2009 May;49(5):1545-53. PMCID:PMC2852109

37. Mosesson MW. Fibrinogen gamma chain functions. J Thromb. Haemost. 2003 Feb;1(2):231-8

38. Migita K, Abiru S, Nakamura M, Komori A, Yoshida Y, Yokoyama T, Daikoku M, Ueki T, Takii Y, Yano K, et al. Lipopolysaccharide signaling induces serum amyloid $A$ (SAA) synthesis in human hepatocytes in vitro. FEBS Lett. 2004 Jul 2;569(1-3):235-9

39. Pruett BS, Pruett SB. An explanation for the paradoxical induction and suppression of an acute phase response by ethanol. Alcohol 2006 Jun;39(2):105-10. PMCID:PMC1764540

40. Bopst M, Haas C, Car B, Eugster HP. The combined inactivation of tumor necrosis factor and interleukin- 6 prevents induction of the major acute phase proteins by endotoxin. Eur J Immunol. 1998 Dec;28(12):4130-7

41. Haziot $A$, Lin $X Y$, Zhang F, Goyert SM. The induction of acute phase proteins by lipopolysaccharide uses a novel pathway that is CD14independent. J Immunol. 1998 Mar 15;160(6):2570-2

42. Sun S, Guo Y, Zhao G, Zhou X, Li J, Hu J, Yu H, Chen Y, Song H, Qiao F, et al. Complement and the alternative pathway play an important role in LPS/D-GalN-induced fulminant hepatic failure. PLoS One 2011;6(11):e26838. PMCID:PMC3206060

43. Kobayashi J, Yamada S, Kawasaki H. Distribution of vitronectin in plasma and liver tissue: relationship to chronic liver disease. Hepatology 1994 Dec;20(6):1412-7

44. Koukoulis GK, Shen J, Virtanen I, Gould VE. Vitronectin in the cirrhotic liver: an immunomarker of mature fibrosis. Hum.Pathol. 2001 Dec;32(12):1356-62 
45. Bacigalupo ML, Manzi M, Rabinovich GA, Troncoso MF. Hierarchical and selective roles of galectins in hepatocarcinogenesis, liver fibrosis and inflammation of hepatocellular carcinoma. World J Gastroenterol. 2013 Dec 21;19(47):8831-49. PMCID:PMC3870534

46. Aziz-Seible RS, Lee SM, Kharbanda KK, McVicker BL, Casey CA. Ethanol feeding potentiates the pro-inflammatory response of Kupffer cells to cellular fibronectin. Alcohol Clin Exp.Res 2011 Apr;35(4):717-25

47. Schonherr E, Witsch-Prehm P, Harrach B, Robenek H, Rauterberg J, Kresse $\mathrm{H}$. Interaction of biglycan with type I collagen. J Biol.Chem. 1995 Feb 10;270(6):2776-83

48. Mohan $\mathrm{H}$, Krumbholz M, Sharma R, Eisele S, Junker A, Sixt M, Newcombe $\mathrm{J}$, Wekerle $\mathrm{H}$, Hohlfeld $\mathrm{R}$, Lassmann $\mathrm{H}$, et al. Extracellular matrix in multiple sclerosis lesions: Fibrillar collagens, biglycan and decorin are upregulated and associated with infiltrating immune cells. Brain Pathol. 2010 Sep;20(5):966-75

49. Tufvesson $\mathrm{E}$, Westergren-Thorsson $\mathrm{G}$. Tumour necrosis factor-alpha interacts with biglycan and decorin. FEBS Lett. 2002 Oct 23;530(1-3):124-8

50. Schaefer L, Babelova A, Kiss E, Hausser HJ, Baliova M, Krzyzankova M, Marsche G, Young MF, Mihalik D, Gotte M, et al. The matrix component biglycan is proinflammatory and signals through Toll-like receptors 4 and 2 in macrophages. J Clin Invest 2005 Aug;115(8):2223-33.

PMCID:PMC1174916

51. Hengst $U$, Albrecht $H$, Hess D, Monard D. The phosphatidylethanolaminebinding protein is the prototype of a novel family of serine protease inhibitors. J Biol.Chem. 2001 Jan 5;276(1):535-40

52. Xu YF, Yi Y, Qiu SJ, Gao Q, Li YW, Dai CX, Cai MY, Ju MJ, Zhou J, Zhang $\mathrm{BH}$, et al. PEBP1 downregulation is associated to poor prognosis in $\mathrm{HCC}$ related to hepatitis B infection. J Hepatol 2010 Nov;53(5):872-9

53. Keller ET, Fu Z, Brennan M. The biology of a prostate cancer metastasis suppressor protein: Raf kinase inhibitor protein. J Cell Biochem. 2005 Feb 1;94(2):273-8

54. Ruiz S, Pergola PE, Zager RA, Vaziri ND. Targeting the transcription factor Nrf2 to ameliorate oxidative stress and inflammation in chronic kidney disease. Kidney Int 2013 Jun;83(6):1029-41. PMCID:PMC3633725

55. Bai Y, Cui W, Xin Y, Miao X, Barati MT, Zhang C, Chen Q, Tan Y, Cui T, Zheng $Y$, et al. Prevention by sulforaphane of diabetic cardiomyopathy is associated with up-regulation of Nrf2 expression and transcription activation. J.Mol.Cell Cardiol. 2013 Apr;57:82-95 
56. Shelton LM, Park BK, Copple IM. Role of Nrf2 in protection against acute kidney injury. Kidney Int 2013 Dec;84(6):1090-5

57. Adachi Y, Moore LE, Bradford BU, Gao W, Thurman RG. Antibiotics prevent liver injury in rats following long-term exposure to ethanol. Gastroenterology 1995 Jan;108(1):218-24

58. Enomoto N, Ikejima K, Yamashina S, Enomoto A, Nishiura T, Nishimura T, Brenner DA, Schemmer P, Bradford BU, Rivera CA, et al. Kupffer cellderived prostaglandin $E(2)$ is involved in alcohol-induced fat accumulation in rat liver. Am.J.Physiol Gastrointest.Liver Physiol 2000 Jul;279(1):G100G106 


\section{ABBREVIATIONS}

$\begin{array}{ll}\text { ALD } & \text { Alcoholic liver disease } \\ \text { BH } & \text { Benjamini-Hochberg } \\ \mathrm{CCl}_{4} & \text { Carbon tetrachloride } \\ \text { CREDL2 } & \text { Cysteine-rich with EGF-like protein domain 2 } \\ \text { ECM } & \text { Extracellular matrix } \\ \text { EtOH } & \text { Ethanol } \\ \text { GnHCl } & \text { Guanidine hydrochloride } \\ \text { GO } & \text { Gene ontology } \\ \text { IPA } & \text { Ingenuity Pathways Analysis } \\ \text { LC-MS/MS } & \text { Liquid chromatography-tandem mass spectrometry } \\ \text { LPS } & \text { Lipopolysaccharide } \\ \text { Nrf2 } & \text { Nuclear factor (erythroid-derived 2)-like 2 } \\ \text { PAS } & \text { Periodic acid-Schiff } \\ \text { RXR } & \text { Retinoid x receptor } \\ \text { SDS } & \text { Sodium dodecyl sulfate } \\ \text { TEABC } & \text { Triethylammonium bicarbonate } \\ \text { TMT } & \text { Tandem mass tag }\end{array}$




\title{
CURRICULUM VITAE
}

\author{
Christine E. Dolin \\ University of Louisville School of Medicine \\ Department of Pharmacology and Toxicology \\ Louisville, KY 40292 \\ cedoli01@louisville.edu \\ 502-852-5157
}

\section{EDUCATION}

2015-present University of Louisville

M.S./Ph.D. Pharmacology and Toxicology

2010-2015 University of Louisville

B.S. Chemistry (conc. Biochemistry), Biology (minor)

\section{PROFESSIONAL EXPERIENCE}

2014-2015 Undergraduate researcher, University of Louisville, Department of Pharmacology and Toxicology

2013 Undergraduate researcher, University of Louisville, Chemistry Department

\section{HONORS}

2017

University of Louisville 3-Minute Thesis Competition Finalist

Graduate Research Fellowship, Integrated Programs in

Biomedical Sciences

2014

NIH R25 Cancer Education Program

2010-2011

University of Louisville Trustee's Scholarship

2010-2011

University of Louisville Alumni Association Scholarship

2010-2014

Kentucky Educational Excellence Scholarship

2010-2011

Oldham County Dollars for Scholars Scholarship, 2010-2011

2010

2010

Valedictorian, South Oldham High School

2009

Commonwealth Diploma

Kentucky Governor's Scholars Program, Biologic and

Environmental Issues

\section{LEADERSHIP}

Resident Assistant, University of Louisville

2013-2014 Student Representative, Green Committee, University of Louisville 


\section{PROFESSIONAL SOCIETIES}

2015-2017

2015-2017

Society of Toxicology

2015-2017

Ohio Valley Chapter of the Society of Toxicology

2013-2015

University of Louisville Alcohol Research Center

American Chemical Society

\section{$\underline{\text { PUBLICATIONS }}$}

\section{Papers}

1. Massey VL, Dolin CE, Poole LG, Hudson SV, Siow DL, Brock GN, Merchant ML, Wilkey DW, Arteel GE. 2017. The hepatic "matrisome" responds dynamically to injury: Characterization of transitional changes to the extracellular matrix in mice. Hepatology 65:969-982

\section{Abstracts - Regional}

1. Dolin CE, Poole LG, Wilkey DW, Rouchka EC, Arteel GE, Barati MT, Merchant ML (2017) Effects of ethanol and lipopolysaccharide on the renal cortex proteome and transcriptome. UT-KBRIN Bioinformatics Summit, Burns, TN.

2. Dolin CE, Poole LG, Wilkey DW, Rouchka EC, Arteel GE, Barati MT, Merchant ML (2017) Effects of ethanol and lipopolysaccharide on the renal cortex proteome and transcriptome. Graduate Student Council Research Symposium, Louisville, KY.

3. Dolin CE, Poole LG, Wilkey DW, Arteel GE, Rouchka EC, Barati MT, Merchant ML (2016) Effects of Ethanol and Lipopolysaccharide on the Renal Cortex Proteome and Transcriptome. Ohio Valley Society of Toxicology Annual Meeting, Indianapolis, IN.

4. Dolin CE, Poole LG, Wilkey DW, Arteel GE, Rouchka EC, Barati MT, Merchant $M L$ (2016) Effects of Ethanol and Lipopolysaccharide on the Renal Cortex Proteome and Transcriptome. Research!Louisville, Louisville, KY.

5. Dolin CE, Poole LG, Wilkey DW, Barati MT, Arteel GE, and Merchant ML (2016) Characterization of the Impact of Ethanol and Lipopolysaccharide on the Renal Cortex Proteome. Ohio Valley Society of Toxicology Summer Meeting, Cincinnati, $\mathrm{OH}$.

6. Dolin CE, Poole LG, Wilkey DW, Barati MT, Arteel GE, and Merchant ML (2016) Characterization of the Impact of Ethanol and Lipopolysaccharide on the Renal Cortex Proteome. University of Kentucky Postdoctoral Symposium, Lexington, KY.

7. Dolin CE, Massey VL, Poole LG, Siow DL, Merchant ML, Wilkey DW, Roman J, and Arteel GE (2016) The Hepatic and Pulmonary "Matrisomes" Respond Dynamically to Inflammatory Injury: Proteomic Characterization of Transitional ECM Changes in the Liver and Lung. Graduate Student Council Research Symposium, Louisville, KY.

8. Dolin CE, Massey VL, Poole LG, Siow DL, Merchant ML, Wilkey DW, Roman J, and Arteel GE (2015). The Hepatic and Pulmonary "Matrisome" Responds Dynamically to Inflammatory Injury: Proteomic Characterization of the Transitional ECM Changes. Research!Louisville, Louisville, KY. 
9. Dolin CE, Massey VL, Poole LG, Siow DL, Merchant ML, Wilkey DW, and Arteel GE (2015) The Hepatic "Matrisome" Responds Dynamically to Stress: Novel Characterization of the ECM Proteome. Atlantic Coast Conference Meeting of the Minds, Raleigh, NC.

10. Dolin CE, Massey VL, Poole LG, Siow DL, Merchant ML, Wilkey DW, and Arteel GE (2015) The Hepatic "Matrisome" Responds Dynamically to Stress: Novel Characterization of the ECM Proteome. Posters at the Capitol, Frankfort, KY.

11. Dolin CE, Massey VL, Poole LG., Siow DL, Merchant ML, Wilkey DW, and Arteel GE (2014) The Hepatic "Matrisome" Responds Dynamically to Stress: Novel Characterization of the ECM Proteome. OVSOT Annual Meeting, Dayton, $\mathrm{OH}$.

12. Dolin CE, Massey VL, Poole LG, Siow DL, Merchant ML, Wilkey DW, and Arteel GE (2014) The Hepatic "Matrisome" Responds Dynamically to Stress: Novel Characterization of the ECM Proteome. Research!Louisville, Louisville, KY.

13. Dolin CE, Massey VL, Poole LG, Siow DL, Merchant ML, Wilkey DW, and Arteel GE (2014) The Hepatic "Matrisome" Responds Dynamically to Stress: Novel Characterization of the ECM Proteome. University of Louisville R25 Cancer Education Program, Louisville, KY.

\section{Abstracts - National}

1. Dolin CE, Poole LG, Wilkey DW, Arteel GE, Rouchka EC, Barati MT, Merchant ML (2016) Omics Characterization of Ethanol and Lipopolysaccharide Impact on the Renal Cortex. American Society of Nephrology Kidney Week, Chicago, IL.

2. Dolin CE, Massey VL, Poole LG, Siow DL, Merchant ML, Wilkey DW, Arteel GE (2015) The Hepatic and Pulmonary "Matrisome" Responds Dynamically to Inflammatory Injury: Proteomic Characterization of the Transitional ECM Changes in the Liver. AASLD's The Liver Meeting, San Francisco, CA.

3. Dolin CE, Massey, VL, Poole LG, Siow DL, Merchant ML, Wilkey DW, and Arteel GE (2015) The Hepatic "Matrisome" Responds Dynamically to Stress: Novel Characterization of the ECM Proteome. SOT Annual Meeting, San Diego, CA.

\section{$\underline{\text { TALKS }}$}

1. Research Seminar, 3/17, A systems-based approach to discover alcohol-induced mechanisms in the liver, lung, and kidney. KBRIN, University of Louisville, Louisville, KY

2. Research Seminar, 6/16, Characterization of the Impact of Ethanol and Lipopolysaccharide on the Renal Cortex Proteome. Ohio Valley Society of Toxicology Student/Post-doc Summer Meeting, University of Cincinnati, Cincinnati, $\mathrm{OH}$

3. Research Seminar, 3/16, Proteomic Characterization of the Impact of AlcoholEnhanced Inflammatory Injury on the Liver, Lung, and Kidney. Department of Pharmacology and Toxicology University of Louisville, Louisville, KY

4. Research Seminar, 6/15, The Hepatic 'Matrisome' Responds Dynamically to Inflammatory Injury: Proteomic Characterization of the Transitional ECM Changes in the Liver. Ohio Valley Society of Toxicology Student/Post-doc Summer Meeting, University of Cincinnati, Cincinnati, $\mathrm{OH}$ 